\title{
Reference solar irradiance spectra and consequences of their disparities in remote sensing of the ocean colour
}

\author{
P. Shanmugam and Y. H. Ahn \\ Ocean Satellite Research Group, Korea Ocean Research and Development Institute, Ansan P.O. Box 29, Seoul 425-600, Korea
}

Received: 5 February 2007 - Revised: 26 March 2007 - Accepted: 31 May 2007 - Published: 29 June 2007

\begin{abstract}
Satellite ocean colour missions require a standard extraterrestrial solar irradiance spectrum in the visible and near-infrared (NIR) for use in the process of radiometric calibration, atmospheric correction and normalization of water-leaving radiances from in-situ measurements. There are numerous solar irradiance spectra (or models) currently in use within the ocean colour community and related domains. However, these irradiance spectra, constructed from single and/or multiple measurements sets or models, have noticeable differences - ranging from about $\pm 1 \%$ in the NIR to $\pm 6 \%$ in the short wavelength region (ultraviolet and blue) - caused primarily by the variation in the solar activity and uncertainties in experimental data from different instruments. Such differences between the applied solar irradiance spectra may have quite important consequences in reconciliation, comparison and validation of the products resulting from different ocean colour instruments. Thus, it is prudent to examine the model-to-model differences and ascertain an appropriate solar irradiance spectrum for use in future ocean colour research and validation purposes. This study first describes the processes which generally require the application of a solar irradiance spectrum, and then investigates the eight solar irradiance spectra (widely in use within the remote sensing community) selected on the basis of the following criteria: minimum spectral range of $350-1200 \mathrm{~nm}$ with adequate spectral resolution, completely or mostly based on direct measurements, minimal error range, intercomparison with other experiments and update of data. The differences in these spectra in absolute terms and in the SeaWiFS and MERIS in-band irradiances and their consequences on the retrieval algorithms of chlorophyll and suspended sediment are analyzed. Based on these detailed analyses, this study puts forward the solar irradiance spectrum most appropriate for all aspects of research, calibration and validation in ocean
\end{abstract}

Correspondence to: P. Shanmugam

(pshanmugam@kordi.re.kr) colour remote sensing. For an improved approximation of the extraterrestrial solar spectrum in the ultraviolet-NIR domain this study also proposes a new solar constant value determined from space-borne measurements of the last three decades.

Keywords. Oceanography: general (Remote sensing and electromagnetic processes) - Solar physics, astrophysics, and astronomy (General or miscellaneous)

\section{Introduction}

The accurate spectral distribution of solar irradiance, produced by the Sun, on a surface perpendicular to its rays, on the outer limit of our atmosphere, is needed in a variety of remote sensing applications, in order to understand the Earth's natural systems and its atmospheric processes. Obtaining such an accurate solar spectrum is difficult, mainly because of two sources of uncertainties - variation in the solar activity and variation in the experimental data. Nevertheless, the variation caused by solar activity (as discussed later) is found to be much smaller than the discrepancies in the absolute spectral irradiance $\left(\mathrm{W} \mathrm{m}^{-2} \mu \mathrm{m}^{-1}\right)$ provided by different instruments with different calibration standards and degradation histories, which complicate the overall assessment of screening out a standard spectrum. The wavelength-dependent discrepancies could also arise from the ground-based observations that are possibly affected by significant absorptions, due to several minor constituents of the Earth's atmosphere, such as ozone, water vapour, nitrogen and carbon components. Due to the difficulties in defining the real instrumental uncertainty at each wavelength and at a specific time, the remote sensing community, over the last three decades, have adopted different solar irradiance spectra for processing the data recorded by various multispectral/ocean colour sensors (Gordon, 1978; Dozier and

Published by Copernicus Publications on behalf of the European Geosciences Union. 
Table 1. Background of the applied solar irradiance spectra in various remote sensing applications.

\begin{tabular}{|c|c|c|c|c|c|}
\hline Solar Irradiance Spectrum & Solar constant & Spectral range $(\mathrm{nm})$ & $\begin{array}{l}\text { Step size / } \\
\text { Increment (nm) }\end{array}$ & Satellite Sensor & References \\
\hline Thekaekara 1973 & 1352.5 & $115-400000$ & $\begin{array}{l}5 \text { (VIS), } 10 \text { (NIR), } \\
>10 \text { (others) }\end{array}$ & MSS & Dozier and Frew (1981) \\
\hline Neckel and Labs 1984 & 1365 & $380-1250$ & 1 & $\begin{array}{l}\text { IRS-P3 MOS, SeaW- } \\
\text { iFS, }\end{array}$ & $\begin{array}{l}\text { Suemnich (1998); Barnes } \\
\text { and Zalewski (2003) }\end{array}$ \\
\hline Wehrli 1985_WMO & 1367 & $199.5-10075$ & $\begin{array}{l}1-2 \text { (VIS, NIR), } \\
<2 \text { (others) }\end{array}$ & $\begin{array}{l}\text { MODIS, Hyperion, } \\
\text { SEVIRI, GOES }\end{array}$ & Doelling et al. (2004) \\
\hline ASTM E-490 & 1366.1 & $119.5-1000000$ & $\begin{array}{l}1 \text { (VIS), } 1-2 \\
\text { (VIS-MIR), } \\
<20 \text { (others) }\end{array}$ & IKONOS & Taylor (2005) \\
\hline ASTM G173-03 & 1366.1 & $280-4000$ & $\begin{array}{l}0.5 \text { (UV), } 1 \\
\text { (VIS-NIR), > } \\
\text { (others) }\end{array}$ & - & - \\
\hline SBDART ETR & & $250-4000$ & $0.5-1$ & - & Ricchiazzi et al. (1998) \\
\hline Gueymard 2004 & 1366.1 & $0.5-1000000$ & $\begin{array}{l}0.5 \text { (UV), } 1 \\
\text { (VIS, NIR), >1 } \\
\text { (others) }\end{array}$ & - & This study \\
\hline Thuillier 2001 and 2003 & 1366.7 & $200-2397$ & $\begin{array}{l}0.3-1 \text { (UV), } 0.1-1 \text { (VIS } \\
\text { and NIR) }\end{array}$ & $\begin{array}{l}\text { SeaWiFS, MODIS, } \\
\text { MERIS, GLI }\end{array}$ & $\begin{array}{l}\text { Delwart (2001); Nieke and } \\
\text { Fukushima (2001); Barnes } \\
\text { and Zalewski (2003); } \\
\text { Brown et al. (2004) }\end{array}$ \\
\hline Thuillier 2004 & $1366.7^{L} / 1367.7^{H}$ & $0.5-2397$ & $\begin{array}{l}0.05 \text { (UV), } 0.05-0.1 \\
\text { (VIS and NIR) }\end{array}$ & GOCI & This study \\
\hline
\end{tabular}

* UV - Ultraviolet, VIS - Visible, NIR - Near infrared, MIR - Middle infrared, L - value for low-activity sun, H - value for high-activity sun.

Frew, 1981; Suemnich, 1998; S. Delwart, 2001 ${ }^{1}$; Nieke and Fukushima, 2001; Barnes and Zalewski, 2003; Doelling et al., 2004; Tayler, 2005). Most of them have been reported during 1973-2004 (Thekaekara, 1973; Neckel and Labs, 1984; Wehrli, 1985; Ricchiazzi et al., 1998 (SBDART ETR); ASTM, 2000 (E-490 and G173-03); Gueymard, 2004; Thuillier, 2004). These irradiance spectra are not monolithic, but rather composites of various spectra recorded by different instruments, in different spectral bands, with different resolution and calibration methods, on different platforms, and at different moments in time. This is the reason why the applied irradiance spectra differ substantially depending on the sources of data in each waveband and resolution, various scaling factors and atmospheric correction procedures.

Table 1 presents the characteristics of various solar irradiance spectra adopted in Earth remote sensing applications over the last three decades. During the early period, Thekaekara was instrumental in presenting some of his primitive AM0 ("air mass zero" extrapolation) irradiance spectra, obtained mostly from research aircrafts and rockets. The author performed considerable corrections and adjustments to compensate for all atmospheric interferences (chiefly by ozone and water vapour), in order to extrapolate irradiances to the top of the atmosphere and reconcile the various radiometric scales in effect. Though the composite spectrum was limited in spectral range and had large uncertainties

\footnotetext{
${ }^{1}$ Delwart, S.: ESA ESTEC, Keplerlan1, 2201 AZ Noordwijk $\mathrm{ZH}$, the Netherlands; personal communication, 2001.
}

from conventional techniques of extrapolation, it became the standard reference spectrum in calibrating early Landsat MSS and other instruments (Dozier and Frew, 1981). In 1984, Neckel and Labs reported a composite solar spectrum from rockets (200-330 nm), high altitude observations (330$1250 \mathrm{~nm})$ and other sources $(>1250 \mathrm{~nm})$. Indeed, this spectrum has been widely accepted for use in scientific applications of many remote sensors, such as CZCS, IRS-P3 MOS and SeaWiFS (Suemnich, 1998; Barnes and Zalewski, 2003). In 1985, the World Meteorological Organization (WMO) of the World Radiometric Centre (WRC) constructed the Wehrli spectrum (AM0) as a composite of four existing data sets: rocket and balloon data (for $200-310 \mathrm{~nm}$ ), scaled spectrum of Arvesen et al. (1969) (for 310-330 nm), Neckel and Labs (1981) (for 330-869 nm) and Smith and Gottlieb (1974) (for $>870 \mathrm{~nm}$ ). Scaling and smoothening were performed in order to match the resulting total irradiance with the solar constant $1367 \mathrm{~W} \mathrm{~m}^{-2}$ (see Table 1). Although such processes introduced noticeable errors in the resulted irradiance values, the Wehrli spectrum remains as the most cited spectrum in the literature and is considered as the reference for MODIS, SEVIRI, GOES and IKONOS sensors (Doelling et al., 2004).

During the recent period, several satellites have been deployed in space to provide modern spectra, which combined with modeled data have rapidly improved the accuracy over existing spectra. The American Society for Testing and Materials (ASTM) has published the ASTM G17303 and ASTM E-490 (AM0) spectra, of these the former is 
quite different from the standard solar spectrum as it represents spectral irradiance on a surface of specified orientation under one set of specified atmospheric conditions. Such a measurement is often influenced by the absorption of large parts of the original solar spectrum by the Earth's atmosphere which blocks or strongly attenuates most of the solar ultraviolet (UV) and infrared radiation (Fligge and Solanki, 2000). In contrast, the latter one is based on data from satellites, space shuttle missions, high-altitude aircraft, rocket soundings, ground-based solar telescopes, and models. In the 119.5 to $410 \mathrm{~nm}$ range, the values are averages of two different instruments on the UARS, SUSIM and SOLSTICE (Woods et al., 1996) (Table 2). In the 410 to $825 \mathrm{~nm}$ range, the values are from the McMath Solar Telescope at Kitt Peak, Arizona (Neckel and Labs, 1984). In the 825 to $4000 \mathrm{~nm}$ range, the values are from the high-resolution solar atlas computed by Kurucz (1984). Scaling and adjustment processes were also involved so that the integrated irradiance is equal to $1366.1 \mathrm{~W} \mathrm{~m}^{-2}$. The drawback with this spectrum is that its resolution is limited to $1 \mathrm{~nm}$ below $630 \mathrm{~nm}$ and $2 \mathrm{~nm}$ above it, which may not be adequate for applications based on the new generation ocean colour missions. The SBDART (Santa Barbara DISORT Atmospheric Radiative Transfer) computes a solar irradiance spectrum based on the LOWTRAN-7 solar spectrum (Thekeakara, 1974) and a composite of information gathered by several different spectral measurement campaigns. The spectral data collected from the Solar Ultraviolet Spectral Irradiance Monitor on Spacelab 2 (VanHoosier et al., 1988) are used for wavelengths between 174 and $351 \mathrm{~nm}$, while the observations of Neckel and Labs (1984) and Wehrli (1985) are used for wavelengths $351-868 \mathrm{~nm}$ and $868-3226 \mathrm{~nm}$, respectively.

In 2004, Gueymard developed a more sophisticated synthetic solar spectrum, which uses vacuum wavelengths below $280 \mathrm{~nm}$ and air wavelengths above $280 \mathrm{~nm}$, and is corrected for 1 ua (astronomical unit). Three resolutions and spectral intervals have been used in the construction of this spectrum, i.e. $0.5 \mathrm{~nm}$ in the UV $(280-400 \mathrm{~nm}), 1 \mathrm{~nm}$ in the visible (VIS) and near-infrared (NIR) (400-1702 nm), and $5 \mathrm{~nm}$ beyond, up to $4000 \mathrm{~nm}$. This is a composite of the weighted average of twenty-three existing measured or modeled spectra from various sources and is constrained to $1366.1 \mathrm{~W} \mathrm{~m}^{-2}$. More recently, new experiments on various space platforms have been performed allowing an observation of the Sun without absorbing the influence of the Earth's atmosphere, for example, the experiments with SOLSPEC spectrometers flown on all three missions of the NASA-sponsored ATLAS and EURECA (Thuillier, 2004). These three spectrometers of SOLSPEC monitor solar irradiance changes in the UV (180$370 \mathrm{~nm})$, VIS (350-900 nm) and IR (800-3000 nm) ranges with a spectral resolution of $1 \mathrm{~nm}$ each, offering the immense advantage of an exceptionally low uncertainty compared to all other experiments. The modern spectrum from these instruments (for 29 March 1992 and 11 November 1994) has been recently released by Thuillier et al. (2004) (henceforth
Table 2. Glossary of experiments/instruments.

\begin{tabular}{|c|c|}
\hline $\mathrm{HF}$ & Hickey-Frieden cavity radiometer \\
\hline ACRIM & $\begin{array}{l}\text { Active Cavity Radiometer Irradiance } \\
\text { Monitor }\end{array}$ \\
\hline SMM & Solar Maximum Mission \\
\hline ERBE & $\begin{array}{l}\text { Earth Radiation Budget Experiment ra- } \\
\text { diometer }\end{array}$ \\
\hline ERBS & Earth Radiation Budget Satellite \\
\hline UARS & Upper Atmosphere Research Satellite \\
\hline VIRGO & $\begin{array}{l}\text { Variability of solar IRradiance and Grav- } \\
\text { ity Oscillations }\end{array}$ \\
\hline SOHO & Solar and Heliospheric Observatory \\
\hline UARS & Upper Atmosphere Research Satellite \\
\hline SUSIM & $\begin{array}{l}\text { Solar Ultraviolet Spectral Irradiance } \\
\text { Monitor }\end{array}$ \\
\hline SOLSTICE & $\begin{array}{l}\text { SOLar STellar Irradiance Comparison } \\
\text { Experiment }\end{array}$ \\
\hline SOLSPE & SOLar SPECtrum \\
\hline ATLAS & $\begin{array}{l}\text { Atmospheric Laboratory for Application } \\
\text { and Science }\end{array}$ \\
\hline EURECA & EUropean Retrievable Carrier \\
\hline GOES & $\begin{array}{l}\text { Geostationary Operational Environmen- } \\
\text { tal Satellites }\end{array}$ \\
\hline MSS & Multi Spectral Scanner \\
\hline MOS & Modular Optoelectronic Scanner \\
\hline SEVIRI & $\begin{array}{l}\text { Spinning Enhanced Visible and Infra- } \\
\text { Red Imager }\end{array}$ \\
\hline MODIS & $\begin{array}{l}\text { Moderate-resolution Imaging Spectrora- } \\
\text { diometer }\end{array}$ \\
\hline GLI & Global Line Imager \\
\hline SeaWiFS & $\begin{array}{l}\text { SeaWiFS stands for Sea-viewing Wide } \\
\text { Field-of-view Sensor }\end{array}$ \\
\hline MERIS & $\begin{array}{l}\text { MEdium Resolution Imaging Spectrom- } \\
\text { eter }\end{array}$ \\
\hline GOCI & Geostationary Ocean Colour Imager \\
\hline
\end{tabular}

“Thuillier 2004 spectrum"), which spans a wavelength range of 0.1 to $2400 \mathrm{~nm}$ with the highest spectral interval of $0.05-$ $0.1 \mathrm{~nm}$. In fact, the previous versions of this spectrum (Table 1) have been recommended for use in the calibration and validation of MERIS and GLI (IOCCG report, 2003) and of SeaWiFS and MODIS (Brown et al., 2004).

This study presents a detailed evaluation of the above described solar irradiance spectra and examines the consequences of their disparities in ocean colour remote sensing. Because different solar irradiance models convert the same radiance or reflectance into different radiance or reflectance, the model-to-model differences are assessed in their absolute terms and in the in-band irradiances computed using the spectral response functions of SeaWiFS and MERIS's channels, which are quite similar to those included in the design of the Geostationary Ocean Colour Imager (GOCI) scheduled for launch in 2008. The consequences of these differences on the retrieval algorithms of chlorophyll and 


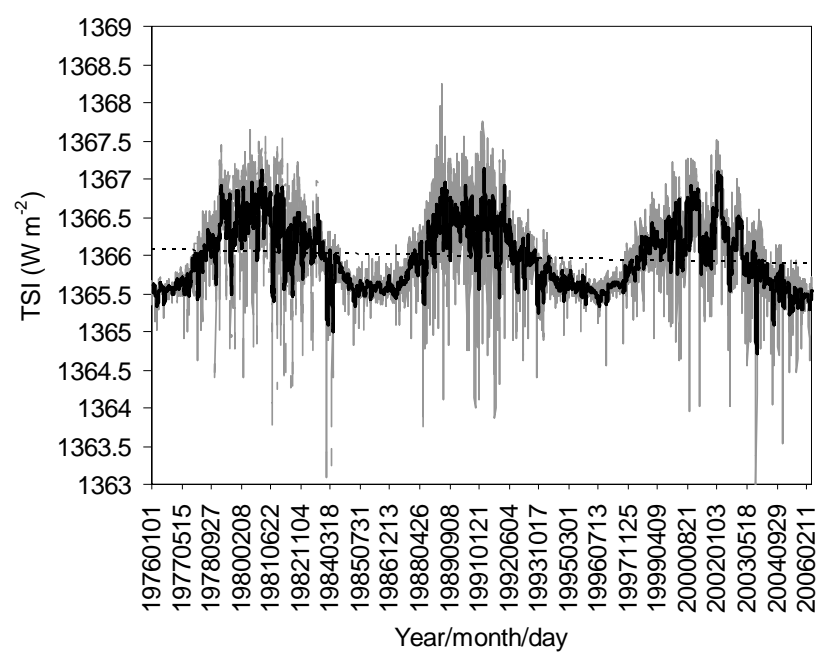

Fig. 1. The variation of total solar irradiance (TSI) during 19762006. The solar constant obtained is $1366.1 \mathrm{~W} \mathrm{~m}^{-2}$. Data are from the HF on Nimbus 7, the ACRIM I on SMM, the ERBE on ERBS, the ACRIM II on UARS, the VIRGO on SOHO, and the ACRIM III on ACRIM-Sat (see Table 2).

suspended sediment are also assessed, and finally, an appropriate irradiance spectrum is put forward for the GOCI development and for the future research and validation in ocean colour remote sensing.

\section{The variation of solar spectral irradiance and the so- lar constant}

The solar spectral irradiance fluctuates depending on the well documented 11-year solar cycle and also the Sun's 27-day rotation cycle. It exhibits strong wavelength dependence with the amount of variability considerably increasing towards shorter wavelengths (Lean, 1991). In the ultraviolet $(1-400 \mathrm{~nm})$ the magnitude of irradiance variations is on the order of $1-14 \%$ and in the visible and NIR part of the spectrum $(>400 \mathrm{~nm})$ it is less than 1\% (Fligge and Solanki, 2000). These variations in the solar irradiance spectrum are mainly caused by the effects of the facular brightening and sunspot darkening. While sunspots dominate short-term changes on time scales of a few days to weeks (Willson and Hudson, 1981), faculae and bright network elements are supposed to live much longer and therefore seem to contribute significantly to the variability of the solar cycle (Pap, 1998). The change in solar activity ultimately causes a variation in the total solar irradiance (TSI), which can be related to the spectral irradiance $\left(E_{o}(\lambda)\right)$ through Eq. (1)

$\mathrm{TSI}=\int_{0}^{\infty} E_{o}(\lambda) d \lambda$.
For studying the variations of TSI, several space-borne radiometers (e.g. the HF on Nimbus 7, the ACRIM I on SMM, the ERBE on ERBS, the ACRIM II on UARS, the VIRGO on SOHO, and the ACRIM III on ACRIM-Sat in Table 2) have been deployed to provide continuous measurements of solar irradiances on a daily basis since late November 1978 (Frohlich and Solanki, 2000; Pap et al., 2002). Because these instruments had a different calibration and degradation problems, the overlapping data sets were originally not in perfect quantitative agreement, even though they agreed qualitatively in the shape and magnitude of the TSI variations during successive solar cycles. Therefore, researchers have made considerable efforts to reconcile time-limited TSI data sets and develop a unique composite time series from the best available data (Pap et al., 2002; Frohlich, 2004). Examples of such a time series are the PMOD, IRMB and ACRIM (http://www.pmodwrc.ch/).

Figure 1 shows the most recent and extended PMOD TSI composite which consists of mean daily values, as well as a 27-day moving average (to dampen short-term effects), together with amplitudes of the three cycles. Note that for interpolation, the data of 1976-1978 generated from empirical models are also included in this composite. It becomes obvious that the absolute minimum and maximum daily solar activity in terms of TSI are $1363 \mathrm{~W} \mathrm{~m}^{-2}$ and $1368.3 \mathrm{~W} \mathrm{~m}^{-2}$ for data sets of 1976-2006, and $1364.7 \mathrm{~W} \mathrm{~m}^{-2}$ and $1367.2 \mathrm{~W} \mathrm{~m}^{-2}$ for 27 -day moving average data sets. These data sets depict the solar constant (i.e. the long-term average of TSI) to be $1366.1 \mathrm{~W} \mathrm{~m}^{-2}$, and the variation of TSI by about $0.16 \%$ over the solar cycle, with 27-day amplitudes normally lower than 11-year amplitudes (Fig. 1). This new solar content is very essential for an improved approximation of the extraterrestrial solar spectrum in the UV- NIR region.

\section{The function of solar irradiance in ocean colour re- mote sensing}

Since most of the Earth's imaging spectrometers are not designed to provide calibrated solar irradiances, knowledge of the absolute spectral values of solar irradiance is required for measurements of the ocean colour from space and in-situ. These values are constant during time and primarily go into the process of radiometric calibration, atmospheric correction algorithms and normalization of water-leaving radiances from in-situ measurements. Radiometric calibration refers to the mapping between instrument response in digital counts and the radiance at the instrument aperture. It is common to define a mean spectral radiance on the basis of measured in-band radiance in Eq. (2) 


$$
L_{i}=\frac{\overline{L_{i}}}{\psi_{i}}=\frac{\int_{0}^{\infty} \phi(\lambda) L(\lambda) d \lambda}{\int_{0}^{\infty} \phi(\lambda) d \lambda},
$$

where $L_{i}$ is the mean spectral radiance, $\overline{L_{i}}$ is the in-band radiance integrated over the spectral bandpass of the relevant channel, $\phi(\lambda)$ is the instrument spectral response function, $L(\lambda)$ is the spectral radiance at the instrument aperture, and $\psi_{i}$ is the effective width of the spectral bandpass. This radiance may be further expressed as a reflectance factor, defined as the ratio of the upwelling radiance over a lambertian surface that would produce the measured in-band radiance, to the irradiance of the extraterrestrial solar beam, as follows,

$\overline{R_{i}}=\frac{\pi \overline{L_{i}}}{\overline{E_{i}^{o}}}$

where $\overline{R_{i}}$ is the reflectance factor and $\overline{E_{i}^{o}}$ is the extraterrestrial solar irradiance integrated over the spectral bandpass of channel $i$. It is important to distinguish the reflectance factor from the top of the atmosphere directional reflectance $\left(R_{i}\right)$ through,

$R_{i}=\frac{\pi \overline{L_{i}}}{\overline{E_{i}^{o}} \cos \theta_{s}}=\frac{\pi \overline{L_{i}}}{\overline{E_{i}^{o}}(1 \mathrm{AU}) r^{-2} \cos \theta_{s}}$,

where $\cos \theta_{s}$ is the solar zenith angle. Note that, for constant in-band radiance the reflectance factor varies during the year, owing to the ellipticity of the Earth's orbit about the Sun. This seasonal variation can be expressed by $\overline{E_{i}^{o}}(1 \mathrm{AU}) r^{-2}$, where $\overline{E_{i}^{o}}(1 \mathrm{AU})$ is the in-band extraterrestrial solar irradiance at one astronomical unit (AU), which is the norm, and $r^{-2}$ is the Sun-Earth distance in AU.

The above term recorded by a satellite sensor at the level of the top of the atmosphere (TOA) is the total reflectance comprising of the complex atmospheric path reflectance, sea surface reflectance and water-leaving reflectance. About 80 $90 \%$ of the total signal results from the atmosphere and sea surface, while the remaining part results from the nearsurface waters of the ocean. This small part carries immense information concerning the ocean biogeochemical variables, including the concentration of phytoplankton which constitutes the first link in the marine food chain. The process of removing the large part of the undesired (atmospheric and sea surface) signal is denoted as an atmospheric correction, which derives the fundamental quantity of water-leaving reflectance that can be related to the optical properties of the water body (i.e. to the substance in it). In remote sensing of the ocean colour, the important, time-independent quantity is the normalized water-leaving radiance $\left[n L_{w}(\lambda)\right]$ which is used in the derivation of in-water algorithms and the estimation of sea water constituents from satellite data. According to Gordon and Clark (1981), the $n L_{w}(\lambda)$ can be obtained by dividing the water-leaving radiance $\left[L_{w}(\lambda)\right]$ by the downwelling irradiance just above the surface $\left[E_{d}\left(0^{+} \lambda\right)\right]$, and then multiplying it by the mean extraterrestrial solar irradiance $\left[\overline{E^{\circ}}(\lambda)\right]$ at the TOA, as in Eq. (5),

$n L_{w}(\lambda)=\left[L_{w}(\lambda) / E_{d}\left(0^{+} \lambda\right)\right] \times \overline{E^{o}}(\lambda)$.

In this equation, ignoring $\overline{E^{o}}(\lambda)$ yields the remote sensing reflectance $\left[R_{r s}\left(0^{+} \lambda\right)\right]$ that is directly related to the inherent optical properties (IOP) of water and substances within it (Ahn et al., 2001) and used to calculate many other quantities related to ocean optics. In the case of in-situ field measurements, both $L_{w}(\lambda)$ and $E_{d}\left(0^{+} \lambda\right)$ can be obtained with field radiometers at the sea. But for satellite sensors that do not measure $E_{d}\left(0^{+} \lambda\right)$, this term is instead computed through Eq. (6)

$E_{d}\left(0^{+} \lambda\right)=\overline{E^{o}}(\lambda) r^{-2} \cos \left(\theta_{s}\right) t_{d}\left(\lambda, \theta_{s}\right)$,

where $\cos \theta_{s}$ is the solar zenith angle and $t_{d}\left(\lambda, \theta_{S}\right)$ is the atmospheric diffuse transmittance in the solar direction with the solar zenith angle of $\theta_{s}$. By introducing this term into Eq. (5) and accounting for the dependency upon the geometrical conditions of satellite observation, one can obtain the satellite-derived normalized water-leaving radiance as follows,

$$
\begin{aligned}
& n L_{w}\left(\lambda, \theta_{s}, \theta_{v}, \Delta \varphi\right)= \\
& \quad L_{w}\left(\lambda, \theta_{s}, \theta_{v}, \Delta \varphi\right) / r^{-2} \cos \left(\theta_{s}\right) t_{d}\left(\lambda, \theta_{s}\right),
\end{aligned}
$$

where $\theta_{v}$ is the viewing angle and $\Delta \varphi$ is the azimuth difference between the solar plane and the plane of observation. Here the satellite observed $n L_{w}\left(\lambda, \theta_{s}, \theta_{v}, \Delta \varphi\right)$ values are independent of the choice of $\overline{E^{o}}(\lambda)$, which is used twice in the calculation, thereby canceling out the spectrum by virtue of the normalization. However, this is not the same case with the in-situ measurement of upwelled radiance, which depends on the choice of $\overline{E^{o}}(\lambda)$ while transforming into $n L_{w}(\lambda)$.

On the other hand, the irradiance reflectance is an apparent optical property defined as the ratio of upwelling irradiance $\left[E_{u}\left(0^{-}, \lambda\right)\right]$ to downwelling irradiance $\left[E_{d}\left(0^{-}, \lambda\right)\right]$, both spectral irradiances are ideally determined at null depth $\left(0^{-}\right)$. Its spectral value from Ahn et al. (2001) is given in Eq. (8),

$R\left(0^{-}, \lambda\right)=\frac{E_{u}\left(0^{-}, \lambda\right)}{E_{d}\left(0^{-}, \lambda\right)}=\frac{Q_{u} L_{u}\left(0^{-}, \lambda, \theta, \Delta \varphi\right)}{(1-\rho) E_{d}\left(0^{+}, \lambda\right)}$.

This quantity essentially depends on the water optical properties and also on illumination conditions. In this equation, $L_{u}\left(0^{-}, \lambda, \theta, \Delta \varphi\right)$ is the upwelling radiance in the direction of zenith $(\theta)$ and azimuth $(\Delta \varphi)$ angles just beneath the surface. In the conversion of $E_{d}\left(0^{-}, \lambda\right)$ to $E_{d}\left(0^{+}, \lambda\right), \rho$ is used, which is the Fresnel reflectance at the air-sea interface for the whole (Sun + sky) downwelling irradiance, typically amounting to within the range of $4-5 \%$ (Morel and Gentili, 1996). It also varies with the sea surface state (wind speed). The $Q_{u}$ function (the ratio of upwelling irradiance to 


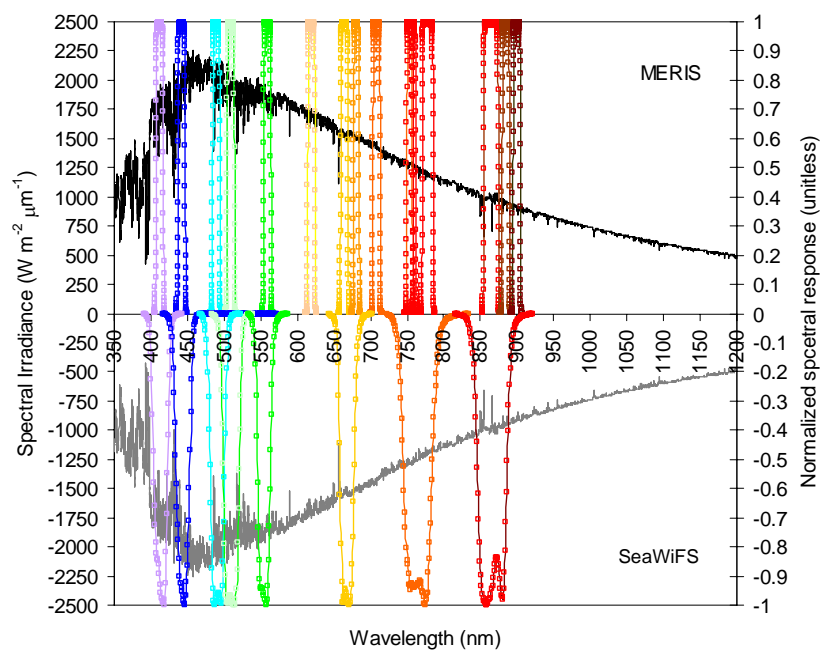

Fig. 2. The spectral response functions (unitless) of SeaWiFS and MERIS superimposed on the Thuillier 2004 irradiance spectrum ( $\mathrm{W} \mathrm{m}^{-2} \mu \mathrm{m}^{-1}$ ). To avoid overlapping of the spectral response functions of SeaWiFS and MERIS, each one is displayed on either side of this plot.

upwelling radiance, $\left(E_{u}\left(0^{-}, \lambda\right) / L_{u}\left(0^{-}, \lambda\right)\right.$, in units of steradians) is not a constant but a function of depth and direction $(\theta, \Delta \varphi)$. The $R\left(0^{-}, \lambda\right)$ quantity can be linked to the normalized water-leaving radiance through Eq. (9) given by Morel and Gentili (1996),

$$
\begin{aligned}
n L_{w}\left(\lambda, \theta_{s}, \theta_{v}, \Delta \varphi\right)= & \overline{E^{o}}(\lambda) R\left(0^{-}, \lambda, \theta_{s}\right) \Re\left(\lambda, \theta_{v} W\right) / \\
& Q_{u}\left(\lambda, \theta_{s} \theta_{v} \Delta \varphi\right),
\end{aligned}
$$

where $\Re$ is a dimensionless quantity equal to 0.529 (Gordon, 2005), as long as $\theta_{v}<40^{\circ}$ (Morel and Belanger, 2006). This quantity combines all the effects of reflection and refraction at the air-sea interface and becomes slightly dependent on the sea state (wind speed). The derived $n L_{w}$ quantity is largely independent of the time of day when measurements are made. Because of this and of the significant dependence on the concentrations of material in the water column, many bio-optical algorithms developed in recent years rely on this quantity to retrieve the accurate information of optically-active constituents (such as the surface concentration of phytoplankton) from satellite measurements in ocean waters (e.g. Müller-Karger et al., 1990; McClain and Yeh, 1994; Aiken et al., 1995; O'Reilly et al., 1998; Ahn et al., 2001; Darecki and Stramski, 2004; Morel and Belanger, 2006; Bailey and Werdell, 2006; Ahn and Shanmugam, 2006).

\section{Major ocean colour missions - SeaWiFS, MERIS and GOCI}

This study considers two major imaging spectrometers, SeaWiFS and MERIS, whose spectral characteristics are quite similar to those of the GOCI proposed by the Korea Ocean Research and Development Institute (KORDI). These imaging spectrometers have the capability of providing an important advantage in studying and understanding the processes at scales of continental shelves and coastal seas. The SeaWiFS, flown on the Orbview-2 SeaStar satellite on a Sunsynchronous orbit (at $705 \mathrm{~km}$ ) in August 1997 by the National Aeronautics and Space Administration (NASA), provides near-global coverage every 2 days of upwelled radiance for eight narrow spectral channels $(\mathrm{nm})$ in the visible and near-infrared spectral domain, with the spatial resolution of $\sim 1 \mathrm{~km} /$ pixel at nadir. The special features of this instrument are that its bands have a bilinear gain response to enable them to avoid saturation over most land and cloud features, it can be tilted to $-20,0$, or +20 degrees to avoid Sun glint reflecting off the oceans, and the resultant data rounded to 10 bit numbers provide high quality information on varying water constituents. On the other hand, the MERIS, flown on its Envisat Earth Observation Satellite (ENVISAT-1) on a Sun-synchronous orbit (at $799.8 \mathrm{~km}$ ) in March 2002 by the European Space Agency (ESA), measures the upwelled radiance for 15 spectral bands in the $412-900 \mathrm{~nm}$ spectral range. It possesses a high spatial $(300 \mathrm{~m})$, spectral, and radiometric resolution (accuracy from 400 to $900 \mathrm{~nm}<2 \%$ and from 900 to $1050 \mathrm{~nm}<5 \%$ ), covering the open ocean and coastal waters with a swath of $1150 \mathrm{~km}$ (Bezy et al., 2000).

In comparison with open ocean applications, coastal applications involving phenomena that vary on shorter space and time scales demand a simultaneous increase in spatial and temporal resolution. To provide an important new capability for imaging the coastal zone, the GOCI is designed to be operated in a staring-frame capture mode on board its Communication Ocean and Meteorological Satellite (COMS) and is tentatively scheduled for launch in 2008. The mission concept includes eight visible-to-near-infrared bands, a $500 \mathrm{~m} \times 500 \mathrm{~m}$ pixel resolution, and a coverage region of $2500 \mathrm{~m} \times 2500 \mathrm{~km}$ centered at $36 \mathrm{~N}$ and $130 \mathrm{E}(\mathrm{KO}-$ RDI report, 2003). The GOCI will provide multiple views of many locations within the fixed region during a single day (i.e. 8 images during the daytime and 2 images during the nighttime) that would help in detecting and monitoring the red tide algal blooms, river plumes and other circulating patterns in the vicinity of the coast. Table 3 provides a comparison between the spectral characteristics of the SeaWiFS, MERIS and GOCI sensors.

Figure 2 displays the normalized spectral response functions (unitless) of SeaWiFS and MERIS superimposed on the Thuillier 2004 irradiance spectrum in the ultraviolet to NIR domain $(350-1200 \mathrm{~nm})$. The SeaWiFS response functions are given at wavelength intervals of $1 \mathrm{~nm}$ (from 400-900 nm) 
and the MERIS response functions are given at wavelength intervals of close to $0.1 \mathrm{~nm}$. Note that, the MERIS spectral bands have almost half the spectral widths of the SeaWiFS bands and their response functions and peaks are narrower and smoother than those of SeaWiFS, which exhibits the lack of smoothness in the peaks of the curves for band $7(765 \mathrm{~nm})$ and $8(865 \mathrm{~nm})$. This may be related to an artifact of the measurement of the band's interference filter designed for SeaWiFS (Hooker et al., 1994). The peak-normalized spectral response functions are input into the model for computing the in-band irradiances of these sensors.

\section{Results}

\subsection{The solar irradiance spectra and their differences}

An exhaustive survey of this study reveals a variety of existing data sets covering the diverse spectral ranges, instrumental sources and measurements periods. Among these data sets only eight irradiance spectra are chosen for this investigation, namely the Thuillier 2004, Neckel and Labs 1984, Wehrli 1985_WMO, ASTM E-490, ASTM G173-03, Gueymard 2004, SBDART ETR, and Thekaekara 1973. Figure 3a displays these eight spectra that vary with wavelength, rising near the green and dropping gradually toward the NIR and abruptly toward the UV part of the spectrum. Figures $3 \mathrm{~b}-\mathrm{d}$ better illustrate the model-to-model differences and the strength and weakness of each of them in the UV, VIS (blue-green) and NIR domains. This intercomparison enables us to identify four types of problems, i.e. localized inaccuracy around a specific wavelength, band underestimations or overestimations, a sharp underestimation structure corresponding to atmospheric absorption interference in uncorrected data (particularly in the NIR), and rapid wavelengthto-wavelength fluctuations close to solar Fraunhofer lines (after Joseph von Fraunhofer in 1814) and other solar absorption features caused by a slight spectral shift between spectra (particularly in the UV, VIS and NIR). It should be noted that the latter experimental problem induces important spikes in the relative differences among these spectra from $350 \mathrm{~nm}$ to $1000 \mathrm{~nm}$, mainly due to the abundance of sharp structures related to Fraunhofer and other absorption lines (Gueymard, 2004). These lines are generally observed as dark features in the solar spectrum and include the $\mathrm{L}$ line of $\mathrm{Fe}$ at $383 \mathrm{~nm}$, the $\mathrm{K}$ line of Ca II at $393.4 \mathrm{~nm}$, the $\mathrm{H}$ line of Ca II at $396.8 \mathrm{~nm}$, the $\mathrm{h}$ line of $\mathrm{H} \delta$ at $410.2 \mathrm{~nm}$, the $\mathrm{G}$ line of $\mathrm{Ca}$ at $430.7 \mathrm{~nm}$, the $\mathrm{G}$ line of $\mathrm{Fe}$ at $430.8 \mathrm{~nm}$, the $\mathrm{G}^{\prime}$ line of $\mathrm{H} \gamma$ at $434 \mathrm{~nm}$, the e line of $\mathrm{Fe}$ at $438.35 \mathrm{~nm}$, the $\mathrm{d}$ line of $\mathrm{Fe}$ at $466.8 \mathrm{~nm}$, the $\mathrm{F}$ line of $\mathrm{H} \beta$ at $486.3 \mathrm{~nm}$, the $\mathrm{c}$ line of $\mathrm{Fe}$ at $495.7 \mathrm{~nm}$, the b4 line of $\mathrm{Mg}$ at $516.73 \mathrm{~nm}$, the b4 line of $\mathrm{Fe}$ at $516.75 \mathrm{~nm}$, the b3 line of $\mathrm{Fe}$ at $516.9 \mathrm{~nm}$, the b2 line of $\mathrm{Mg}$ at $517.27 \mathrm{~nm}$, the b1 line of $\mathrm{Mg}$ at $518.3 \mathrm{~nm}$, the $\mathrm{E}_{2}$ line of $\mathrm{Fe}$ at $527 \mathrm{~nm}$, the $\mathrm{D}_{3}$ line of $\mathrm{He}$ at $587.56 \mathrm{~nm}$, the $\mathrm{D}_{2}$ line of $\mathrm{Na}$ at $588.9 \mathrm{~nm}$, the $\mathrm{D}_{1}$ line of $\mathrm{Na}$ at $589.6 \mathrm{~nm}$, the $\mathrm{C}$ line of $\mathrm{H} \alpha$ at $656.3 \mathrm{~nm}$, and other absorption lines at 850,854 and $866 \mathrm{~nm}$. Besides these lines, there are also the Earth's telluric absorption lines related to molecular oxygen $\left(\mathrm{O}_{2}\right)$, carbon monoxide $(\mathrm{CO})$, and other molecules that contribute particularly to the NIR.

Consider the Thuillier 2004 spectrum, because of its high spectral resolution all major Fraunhofer lines seem to be deeper and narrower than those in other spectra. In the cases of Gueymard 2004, ASTM E-490 and ASTM G173-03 spectra, the absorption lines are quite identical in shape and depth though their spectral positions deviate slightly from the Thuillier 2004 spectrum. In contrast, the Neckel and Labs 1984, Wehrli 1985_WMO and SBDART ETR spectra show the spectrally shifted, reduced lines at these specific wavelengths and the Thekaekara 1973 irradiance does not bring this variability to our observation, owing to its limited spectral resolution. Perhaps the change in solar activity could also cause such differences around the Fraunhofer lines (Gueymard, 2004).

Not surprisingly, the large differences are also observed among eight irradiance spectra in the three plots of UV (375-425 nm), VIS (450-500 nm) and NIR (825-875 nm) (Figs. 3b-d). These differences increase from the NIR to VIS and become very prominent in the UV region. To better illustrate the magnitude of these differences, the irradiance values of each reference spectrum are averaged for the above wavelength ranges and the differences with the Thuillier 2004 spectrum (taken as the reference because it represents the current state of the art in solar irradiance spectra of exceptionally low uncertainty compared to others; Rottman et al., 2004) are calculated and given in Table 4. In both the absolute and band-averaged terms $\left(\mathrm{W} \mathrm{m}^{-2} \mu \mathrm{m}^{-1}\right.$ ), the Thuillier 2004 spectrum is relatively higher in the UV and VIS and shows consistency with other spectra in the NIR (except Fraunhofer lines). While taking the difference with the Thuillier 2004 spectrum, the Gueymard 2004 spectrum seems to be closer to the Thuillier 2004 spectrum at $450-500 \mathrm{~nm}$, but differs substantially by -213.30 and $-8.71 \mathrm{~W} \mathrm{~m}^{-2} \mu \mathrm{m}^{-1}$ at $375-425 \mathrm{~nm}$ and $825-875 \mathrm{~nm}$, respectively. The Thekaekara 1973 spectrum, though exhibiting relatively less of a difference at UV and VIS (blue), yields a large negative difference with the Thuillier 2004 at NIR (the absolute term also explains this difference seen from 500-900 nm). The differences in the Wehrli 1985_WMO, ASTM E-490 and SBDART ETR spectra are generally less at $825-875 \mathrm{~nm}\left(0.18,-1.14\right.$ and $0.79 \mathrm{~W} \mathrm{~m}^{-2} \mu \mathrm{m}^{-1}$, respectively), but are significant at $450-500 \mathrm{~nm}(-56.50$, -58.50 and $-51.17 \mathrm{~W} \mathrm{~m}^{-2} \mu \mathrm{m}^{-1}$, respectively) and 375$425 \mathrm{~nm}\left(-150.97,-151.85\right.$ and $-151.85 \mathrm{~W} \mathrm{~m}^{-2} \mu \mathrm{m}^{-1}$, respectively). Among the ASTM G173-03 and Neckel and Labs 1984 spectra, the ASTM G173-03 appears to be closer to the Thuillier 2004 than the Neckel and Labs 1984 at $825-875 \mathrm{~nm}$ and $450-500 \mathrm{~nm}$. However, at $375-425 \mathrm{~nm}$ the situation becomes reversed, i.e. the ASTM G173-03 differs by a factor of $-240.38 \mathrm{~W} \mathrm{~m}^{-2} \mu \mathrm{m}^{-1}$ larger than $-133.01 \mathrm{~W} \mathrm{~m}^{-2} \mu \mathrm{m}^{-1}$ for the Neckel and Labs 1984. 
Table 3. The characteristics of SeaWiFS, MERIS and GOCI sensors.

\begin{tabular}{llll}
\hline \multicolumn{3}{c}{ Centre Wavelength \pm Bandwidth(nm) } & Application/mission objectives \\
SeaWiFS & MERIS & GOCI & \\
\hline $412 \pm 20$ & $412.5 \pm 10$ & $412 \pm 20$ & Yellow substance and detrital matter \\
$443 \pm 20$ & $442.5 \pm 10$ & $443 \pm 20$ & Chlorophyll absorption maximum \\
$490 \pm 20$ & $490 \pm 10$ & $490 \pm 20$ & Chlorophyll and other pigments \\
$510 \pm 20$ & $510 \pm 10$ & & Suspended sediment, red tides \\
$555 \pm 20$ & $560 \pm 10$ & $555 \pm 20$ & Chlorophyll reference, suspended sediments \\
& $620 \pm 10$ & & Suspended sediments \\
$670 \pm 20$ & $665 \pm 10$ & $660 \pm 10$ & Chlorophyll absorption and fluorescence base 1 \\
& $681.25 \pm 7.5$ & $680 \pm 10$ & Chlorophyll fluorescence peak \\
& $708.75 \pm 10$ & & Atmospheric correction, fluorescence base 2 \\
& $753.75 \pm 7.5$ & & Vegetation, cloud \\
$765 \pm 40$ & $760.625 \pm 3.75$ & $745 \pm 20$ & Chlorophyll fluorescence base 2, Oxygen absorption (in case of MERIS) \\
& $778.75 \pm 15$ & & Atmospheric correction, vegetation \\
$865 \pm 40$ & $865 \pm 20$ & $865 \pm 40$ & Water vapour reference, vegetation \\
& $885 \pm 10$ & & Atmospheric correction \\
& $900 \pm 10$ & & Water vapour, land \\
\hline
\end{tabular}

Table 4. The band-averaged values and their differences with the Thuillier 2004 spectrum.

\begin{tabular}{lllllll}
\hline Solar irradiance spectrum & $\begin{array}{l}\text { Band average } \\
(375-425 \mathrm{~nm})\end{array}$ & $\begin{array}{l}\text { Difference with the } \\
\text { Thuillier 2004 }\end{array}$ & $\begin{array}{l}\text { Band average } \\
(450-500 \mathrm{~nm})\end{array}$ & $\begin{array}{l}\text { Difference with the } \\
\text { Thuillier 2004 }\end{array}$ & $\begin{array}{l}\text { Band average } \\
(825-875 \mathrm{~nm})\end{array}$ & $\begin{array}{l}\text { Difference with the } \\
\text { Thuillier 2004 }\end{array}$ \\
\hline Thuillier 2004 & 1556.99 & 0.00 & 2045.07 & 0.00 & 1007.39 & 0.00 \\
Neckel and Labs 1984 & 1423.98 & -133.01 & 1990.49 & -54.58 & 1018.86 & 11.46 \\
Wehrli 1985_WMO & 1406.02 & -150.97 & 1988.57 & -56.50 & 1007.58 & 0.18 \\
ASTM E-490 & 1405.14 & -151.85 & 1986.57 & -58.50 & 1006.25 & -1.14 \\
ASTM G173-03 & 1316.61 & -240.38 & 1992.30 & -52.77 & 1005.22 & -2.17 \\
Gueymard 2004 & 1343.68 & -213.30 & 2055.10 & 10.03 & 998.69 & -8.71 \\
SBDART ETR & 1405.14 & -151.85 & 1993.90 & -51.17 & 1008.19 & 0.79 \\
Thekaekara 1973 & 1427.27 & -129.71 & 2042.33 & -2.74 & 991.43 & -15.96 \\
\hline
\end{tabular}

Figure $3 \mathrm{e}$ better illustrates the differences in these eight spectra, normalized by the peak value at $451 \mathrm{~nm}$. The observed differences are indeed much higher than the $0.16 \%$ of the solar-induced variability in the UV-NIR domain and can be related to the instrumental uncertainty and calibration problems, and ineffective atmospheric correction procedures.

5.2 The SeaWiFS and MERIS in-band solar irradiances and their differences

The Earth observation sensors, like SeaWiFS and MERIS, do not carry independent devices to provide calibrated solar irradiances to transform their measurements to reflectances at the TOA. Consequently, they depend on a single solar irradiance spectrum from instruments specifically designed for measuring the Sun. Because different irradiance spectra convert the TOA signal into different reflectances, this study judiciously examines the model-to-model differences in terms of the in-band irradiances $\left(\overline{E_{i}^{o}}\right)$, computed using the spectral response functions of SeaWiFS and MERIS's channels, as follows,

$\overline{E_{i}^{o}}=\frac{\int_{0}^{\infty} \phi(\lambda) \overline{E^{o}}(\lambda) d \lambda}{\int_{0}^{\infty} \phi(\lambda) d \lambda}$,

where $\phi(\lambda)$ is the relative spectral response of the SeaWiFS or MERIS's channel $(i)$, and $\overline{E^{o}}(\lambda)$ is the spectral irradiance from different models interpolated to the wavelength interval of $1 \mathrm{~nm}$ and $0.1 \mathrm{~nm}$ for the SeaWiFS and MERIS spectral responses, respectively. Figures $4 \mathrm{a}$ and $\mathrm{b}$ depict the characteristics of the eight solar irradiances with partially or completely removed Fraunhofer lines after being transformed into the SeaWiFS and MERIS's in-band irradiances. As was noted before, the large differences exist between them, particularly in the UV-VIS $(412-510 \mathrm{~nm})$, where the Gueymard 2004 spectrum is higher followed by the Thuillier 2004 and other spectra. 


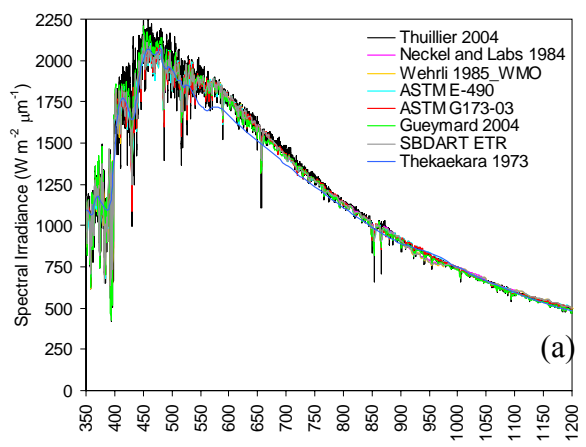

Wavelength $(\mathrm{nm})$

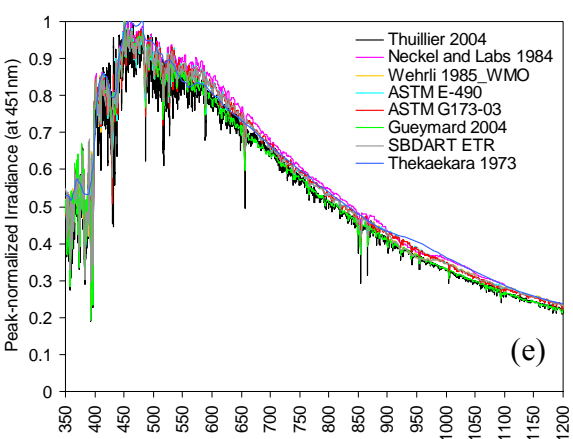

Wavelength $(\mathrm{nm})$
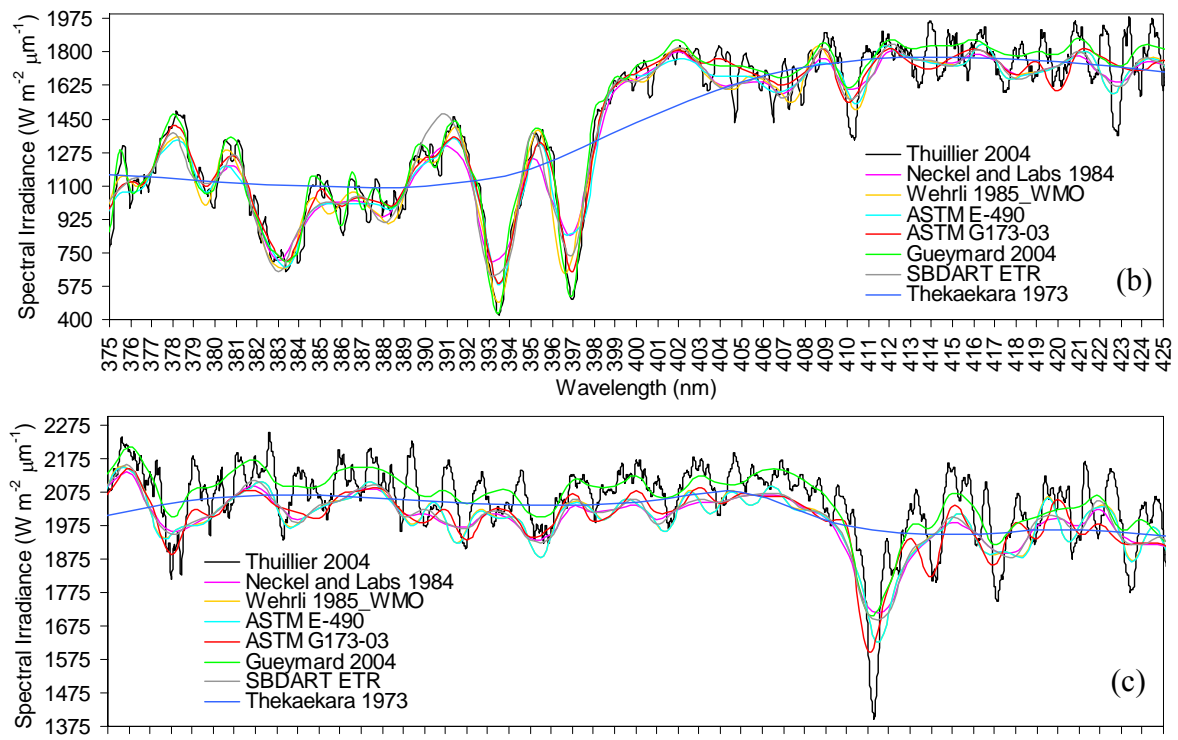

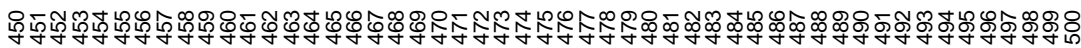
Wavelength $(\mathrm{nm})$

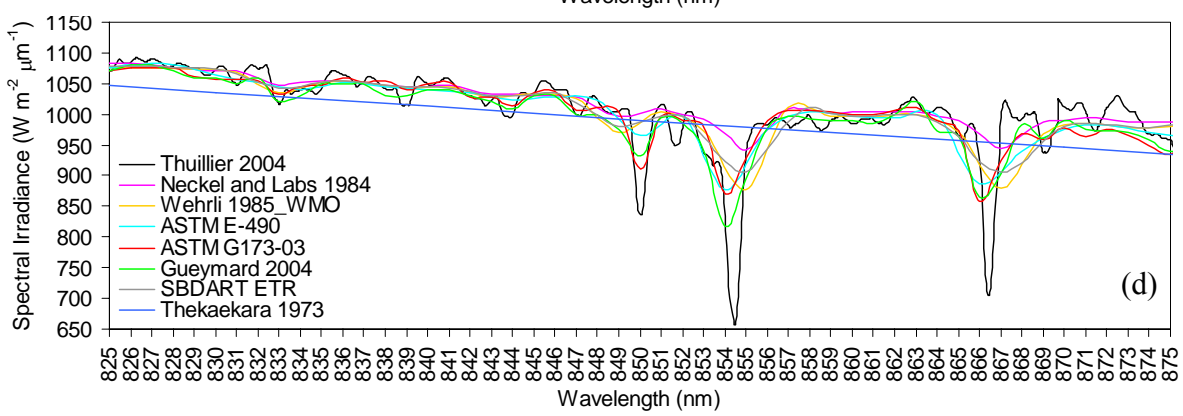

Fig. 3. (a) The spectral irradiance of the eight reference spectra in the UV to NIR (from 350-1200 nm) domains, (b-d) their magnified portions in the ultraviolet-blue-green and NIR, and (e) the peak-normalized irradiance values (at $451 \mathrm{~nm}$ ) in the 350-1200 nm range.

Figures 5a and $\mathrm{b}$ provide an assessment of the percent differences between the Thuillier 2004 and other spectra in the SeaWiFS and MERIS channels. In the case of SeaWiFS (Fig. 5a), the difference in the Gueymard 2004 is at a minimum of $0.24 \%$ at $555 \mathrm{~nm}$ and at a maximum of $-2.21 \%$ at $412 \mathrm{~nm}$, whereas in the Neckel and Labs 1984, Wehrli 1985_WMO, ASTM E-490, ASTM G173-03 and SBDART ETR the differences are in the range of $-0.90-0.11 \%$ at $865 \mathrm{~nm}$ and $1.38-2.51 \%$ at $443 \mathrm{~nm}$ (and slightly lower
$0.57-1.47 \%$ at $412 \mathrm{~nm}$ ). Such large differences in the 412 and $443 \mathrm{~nm}$ regions of major spectral lines (h line of $\mathrm{H} \delta$ at $410.2 \mathrm{~nm}$ and e line of Fe at $438.35 \mathrm{~nm}$ ) can be tentatively explained by changes in the solar activity, uncertainties in the experimental data and spectral resolution of data. The Thekaekara 1973 spectrum shows the progressively high differences of $2.87 \%$ at $443 \mathrm{~nm}$ and $0.7-7.64 \%$ at NIR, which confirms the previous findings by Frohlich (1983). In the case of MERIS that includes several narrow and additional 

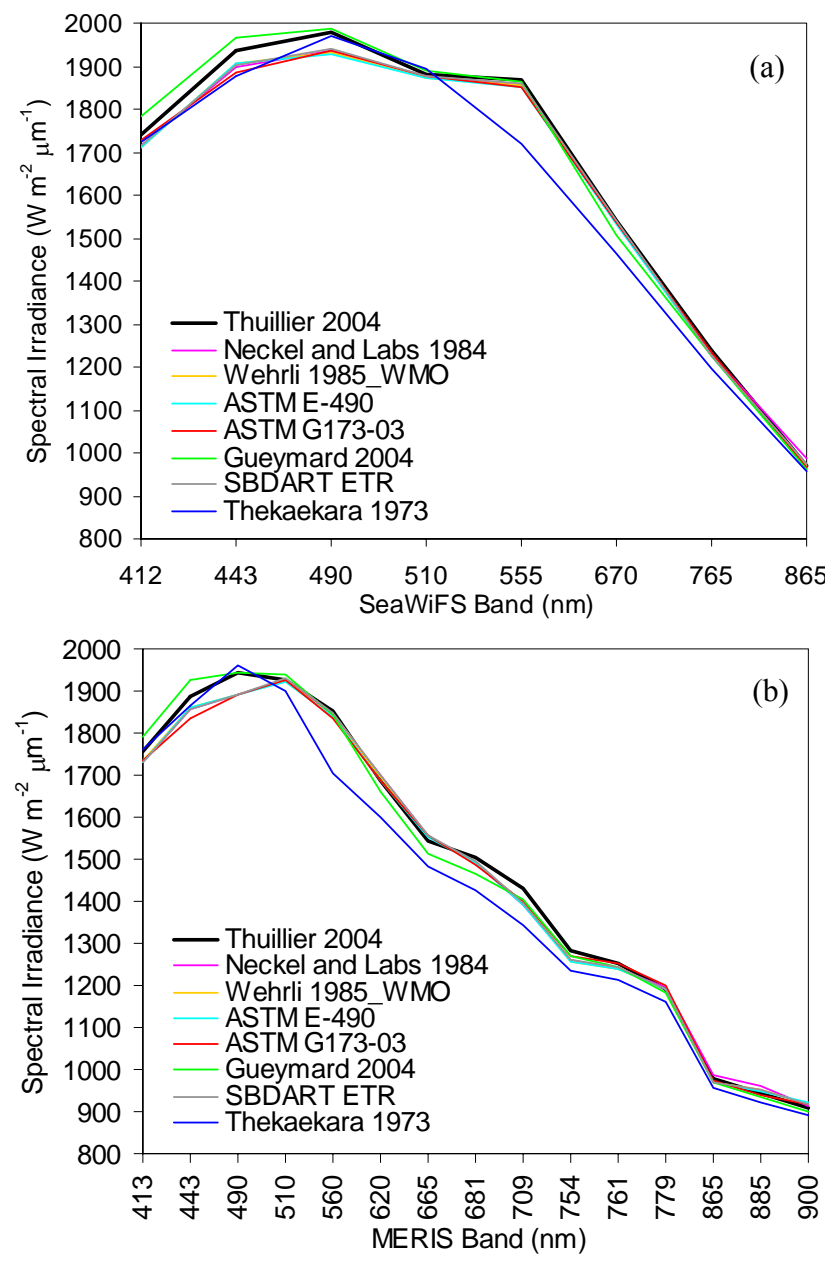

Fig. 4. The in-band irradiances for SeaWiFS (a) and MERIS (b).

channels, the above differences are further magnified and the new peaks and valleys appear to be prominent at 620,681 , 709, 754, 779, 885 and $900 \mathrm{~nm}$ (Fig. 5b). Perhaps a portion of this magnification in the differences of the in-band irradiance spectra can be explained by several absorption lines close to the MERIS channels in the UV-NIR region (particularly 412, 443, 490, 665 and $865 \mathrm{~nm}$ ). Consider the Gueymard 2004 spectrum, the percent differences with the Thuillier 2004 spectrum are small at $0.81-1.13 \%$ in the NIR channels $(754-900 \mathrm{~nm})$ but significantly larger in the blue (413 and $443 \mathrm{~nm})$ and red (620-709 nm) channels. This may be attributable to an inappropriate scaling factor applied to lessen the difference of its spectral irradiance with other sources of data and differences in the calibration between various measurements. The differences (minimal and maximal) in the Neckel and Labs 1984, Wehrli 1985_WMO, ASTM E-490, ASTM G173-03, and SBDART ETR spectra are of the order of $-1.6-5.24 \%,-1.26-5.07 \%,-1.36-5.27 \%,-1.25-$ $5.35 \%$ and $-1.52-5.10 \%$. This is in contrast with $-1.83-$ $14.6 \%$ for the Thekaekara 1973 spectrum which highly fluctuates with the Thuillier 2004 at wavelengths above $510 \mathrm{~nm}$.
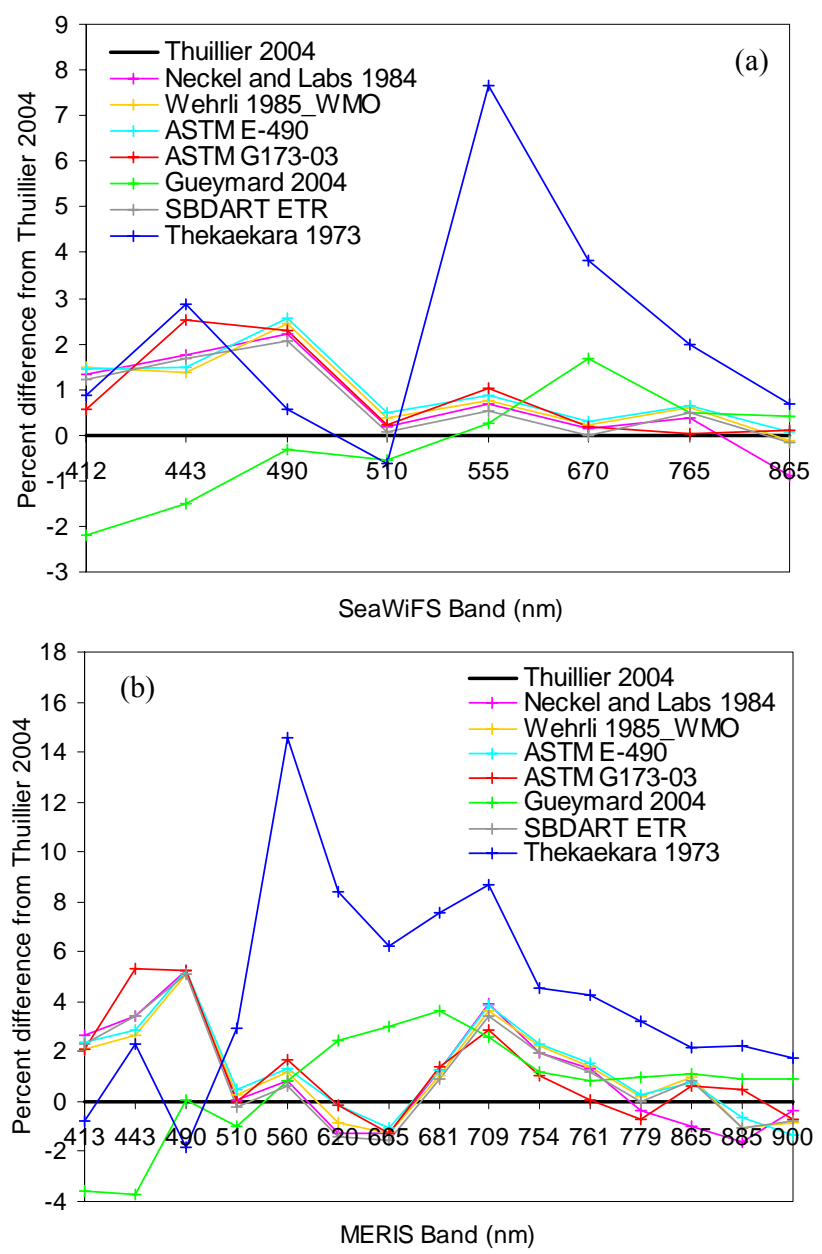

Fig. 5. The percent differences between the Thuillier 2004 and other spectra in SeaWiFS and MERIS channels.

Table 5 gives the band-averaged percent differences between the Thuillier 2004 and other spectra in the SeaWiFS and MERIS channels. Overall, the differences in the Gueymard 2004 spectrum are radically small when comparing with the others. Among the older spectra, the Neckel and Labs 1984 and SBDART ERT closely resemble each other in the differences with the Thuillier 2004, and the Wehrli 1985_WMO is slightly higher but reasonable when comparing with the ASTM G173-03 and ASTM E-490 spectra. The Thekaekara 1973 spectrum claims inaccuracy due to the inclusion of terrestrial absorption features resulting from aircraft measurements.

5.3 The in-situ radiometric measurements and normalization

The extraterrestrial solar irradiance spectrum is involved in the process of transforming sea-truth (in-situ) measurements of water-leaving radiance $\left(\mathrm{L}_{w}\right)$ into normalized water-leaving radiance $\left(\mathrm{nL}_{w}\right)$ and subsequently predicting 
Table 5. The band-averaged percent differences with the Thuillier 2004 spectrum.

\begin{tabular}{llllllll}
\hline Sensor & Neckel and Labs 1984 & Wehrli 1985_WMO & ASTM E-490 & ASTM G173-03 & Gueymard 2004 & SBDART ETR & Thekaekara 1973 \\
\hline MERIS & 0.987845 & 1.112088 & 1.272651 & 1.198229 & 0.677517 & 0.97962 & 4.416144 \\
SeaWiFS & 0.719042 & 0.886044 & 0.975329 & 0.870834 & -0.21814 & 0.728499 & 2.221714 \\
\hline
\end{tabular}

the retrieval algorithms of the sea water constituents. To analyze the impact of the irradiance differences on these processes, the radiometric measurements of downward spectral irradiance $\mathrm{E}_{d}(\lambda)$, total water leaving radiance $\mathrm{tL}_{w}(\lambda)$ and sky radiance $\mathrm{L}_{\text {sky }}(\lambda)$ collected during the period 1998-2004 of R/V (Research Vessel) Olympic cruises in the Korean South Sea (KSS) and Korean Southwest Sea (KSWS), R/V EARDO cruises in the East Sea (ES) and East China Sea (ECS), and R/V TAMGU cruises in the Yellow Sea, were processed. These measurements were performed at various sample sites using an ASD FieldSpec Pro Dual VNIR Spectroradiometer with a spectral range from $350-1050 \mathrm{~nm}$ and a spectral sample interval of $1.4 \mathrm{~nm}$. This instrument was calibrated and several inter-calibrations with other instruments were performed to confirm its stability. The data recorded in units of $\mathrm{mW} \mathrm{cm}^{-2} \mu \mathrm{m}^{-1} \mathrm{sr}^{-1}$ were corrected for the contribution of skylight reflection and air-sea interface effects, in order to obtain $L_{w}(\lambda)=t L_{w}(\lambda)-F_{r}(\lambda) \times L_{\text {sky }}(\lambda)$, where the $F_{r}$ value was kept equal to 0.025 (Austin, 1974), in spite of its variability with viewing geometry, sky conditions and sea surface roughness due to wind (Mobley, 1999). For all the cruises, the concentrations of chlorophyll (Chl), suspended sediment (SS) and dissolved organic matter (DOM) were determined based on the standard spectrophotometric procedures and oven-drying method (Jeffrey and Humphrey, 1975; Ahn et al., 2001).

Figure 6 shows an example of the water-leaving radiance spectra collected in phytoplankton-dominated, turbid and relatively clear waters of the KSS, KSWS and southern YS during September 2002, February 2003 and August 2003. In highly turbid KSWS waters containing $\mathrm{Chl}=0.6-$ $1.6 \mathrm{mg} \mathrm{m}^{-3}, \mathrm{SS}=13-25 \mathrm{~g} \mathrm{~m}^{-3}$ and $\mathrm{DOM}=1.2-1.8 \mathrm{~m}^{-1}$, the $L_{w}$ spectra progressively increase with increasing turbidity and show three prominent peaks around $550-600 \mathrm{~nm}$, 625-675 and 760-820 nm, attributable to the enhancement of backscattering by SS. The low $L_{w}$ values in the shorter wavelength domain may be caused by the enhancement of absorption by weakly coloured sediment particles. In relatively clear YS waters containing $\mathrm{Chl}=0.8-1.2 \mathrm{mg} \mathrm{m}^{-3}$, $\mathrm{SS}=1.5-6 \mathrm{~g} \mathrm{~m}^{-3}$ and $\mathrm{DOM}=0.14-0.25 \mathrm{~m}^{-1}$, the $L_{w}$ values are slightly high in the green and blue and low in the red and near-infrared wavelengths because of profound absorption by the seawater. In phytoplankton-dominated KSS waters containing $\mathrm{Chl}=12-21 \mathrm{mg} \mathrm{m}^{-3}, \mathrm{SS}=7-11 \mathrm{~g} \mathrm{~m}^{-3}$ and DOM=0.5$0.7 \mathrm{~m}^{-1}$, the weak $L_{w}$ signals in the lower green and blue are due to the combined absorption by phytoplankton pigments, DOM and other non-living suspended matters, and the strong $L_{w}$ signals in the green and red wavelengths are due to the minimal total absorption and chlorophyll-a fluorescence (Morel and Prieur, 1977; Gitelson et al., 1994; Ahn et al., 2001).

While the different $\overline{E^{o}}(\lambda)$ spectra were adopted to transform measurements of $L_{w}$ into $\mathrm{nL}_{w}$ in the SeaWiFS and MERIS channels, the differences observed were notably high, particularly in turbid and relatively clear waters (Figs. 7a and b). In phytoplankton-dominated waters, the absolute $\mathrm{nL}_{w}$ differences between the Thuillier 2004 and other spectra (Neckel and Labs 1984, Wehrli 1985_WMO, ASTM E-490, ASTM G173-03, SBDART ETR and Gueymard 2004) are within \pm 0.01 . The Thekaekara 1973 has as expected a large difference with the Thuillier 2004 spectrum, particularly at $555 \mathrm{~nm}$ and $560 \mathrm{~nm}$. In the case of turbid waters, the $\mathrm{nL}_{w}$ differences between the Thuillier 2004 and other spectra (except for the Thekaekara 1973) are within \pm 0.03 at $412 \mathrm{~nm}$, but positively or negatively magnified toward the longer wavelengths (particularly at 443$490 \mathrm{~nm}, 555-560 \mathrm{~nm}$ and 620-754 nm). The Thekaekara 1973 spectrum holds large $\mathrm{nL}_{w}$ differences (additional channels of MERIS better accentuate the differences) in these wavelengths, probably caused by the terrestrial absorption features and atmospheric inferences with airborne measurements.

Figure 8 compares the band-averaged $\mathrm{nL}_{w}$ differences between the Thuillier 2004 and other spectra in the SeaWiFS and MERIS channels. Due to fewer band numbers with almost double the spectral widths of the MERIS channels, the SeaWiFS band-averaged differences for all three situations seem to be slightly higher than the MERIS bandaveraged differences. However, this illustration allows us to obtain the following order (from lower to higher $\mathrm{nL}_{w}$ differences with the Thuillier 2004 regardless of the water types): (1) the Gueymard 2004, (2) the SBDART ETR, (3) the Neckel and Labs 1984, (4) the ASTM 173-03, (5) the Wehrli 1985_WMO, (6) the ASTM E-490, and (7) the Thekaekara 1973. 


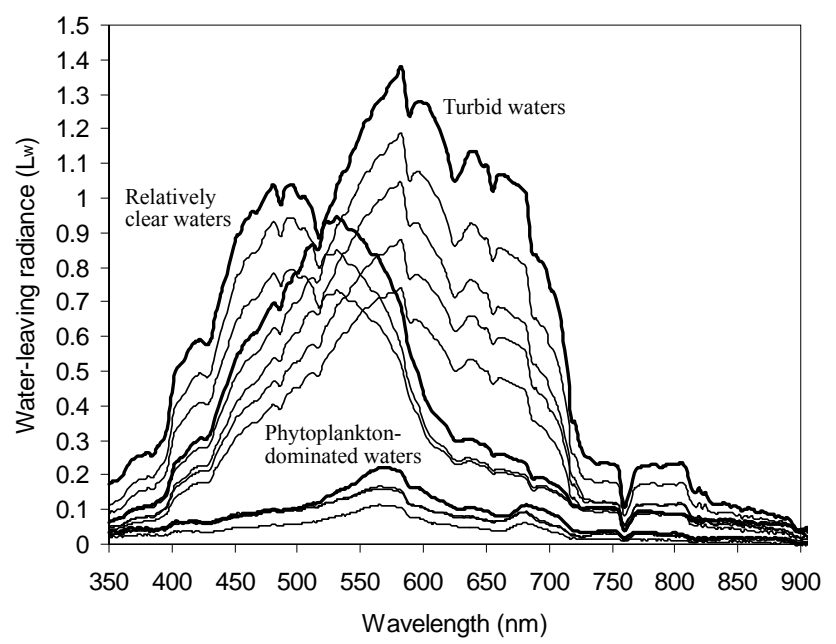

Fig. 6. The water-leaving radiance spectra collected in phytoplankton-dominated, turbid and relatively clear waters of the KSS, KSWS and southern YS.

5.4 The ocean colour retrieval algorithms and their compatibility

The consequences of the wavelength-dependent irradiance differences have also been investigated on the multi-band and single-band algorithms used to retrieve chlorophyll and suspended sediment concentrations in ocean waters. The multiband algorithms take advantage of decreased radiance (or reflectance) in the blue $(440-510 \mathrm{~nm})$ and increased radiance (or reflectance) in the green $(550-565 \mathrm{~nm}$ ) by working in terms of the ratios in these two wavelengths. These algorithms are therefore called the blue-to-green ratio algorithms which estimate $\mathrm{Chl}$ concentrations (e.g. the SeaWiFS OC2 $(\lambda 1=443 \mathrm{~nm}$ and $\lambda 2=490 \mathrm{~nm})$, the SeaWiFS or MERIS OC4 $(\lambda 1=443,490$, or $555 \mathrm{~nm}$, and $\lambda 2=555$ or $560 \mathrm{~nm})$, the OCTS Chl_a $(\lambda 1=520,565 \mathrm{~nm}$ and $\lambda 2=490 \mathrm{~nm})$, the MODIS DAAC $\mathrm{v} 4(\lambda 1=443$ and $\lambda 2=550)$ and the GLI OC4 $(\lambda 1=443,460$, or $520 \mathrm{~nm}$, and $\lambda 2=545 \mathrm{~nm}$ ); Clark, 1997; O'Reilly et al., 1998, 2000; Mitchell, 2001; Pinkerton et al., 2005). The singleband algorithms primarily rely on the enhanced radiance (or reflectance or backscattering) in the green-NIR (where sediment absorption is weak, and the algal and yellow substance absorptions are minimal) to estimate SS concentrations (e.g. the Landsat-MSS and TM, SeaWiFS, MERIS and SPOT algorithms; Klemas et al., 1974; Stumpf and Pennock, 1991; Ahn et al., 2001, 2005; Doxaran et al., 2002; Ruddick et al., 2003; Acker et al., 2004; Morel and Belanger, 2006); these algorithms perform better at SS retrievals than the spectral ratio algorithms that are susceptible to failure in the presence of other particulate organic and dissolved matters in proximity to the coastal areas (Ahn et al., 2001; Binding et al., 2003).

The large in-situ bio-optical data sets collected from a wide range of waters $\left(\mathrm{Chl}=0.1-107 \mathrm{mg} \mathrm{m}^{-3}, \mathrm{SS}=0.13-\right.$
$120 \mathrm{~g} \mathrm{~m}^{-3}$, and $\mathrm{DOM}=0.01-2 \mathrm{~m}^{-1}$ ) around the Korean peninsula and neighboring regions were used to derive the following relationships for SeaWiFS and MERIS: SeaWiFS_Thuillier $2004\left[\mathrm{~nL}_{w}(490) / \mathrm{nL}_{w}(555)\right]$ vs. SeaWiFS_Others $\quad\left[\mathrm{nL}_{w}(490) / \mathrm{nL}_{w}(555)\right], \quad$ MERIS_Thuillier $2004 \quad\left[\mathrm{~nL}_{w}(490) / \mathrm{nL}_{w}(560)\right] \quad$ vs. MERIS_Others $\left[\mathrm{nL}_{w}(490) / \mathrm{nL}_{w}(560)\right], \quad$ and MERIS_Thuillier 2004 $\left[\mathrm{nL}_{w}(620)\right]$ vs. MERIS_Others $\left[\mathrm{nL}_{w}(620)\right]$, for assessing the disparities between the Thuillier 2004 and others in the ratio terms, and SeaWiFS $\left[\mathrm{nL}_{w}(490) / \mathrm{nL}_{w}(555)\right]$ and MERIS $\left[\mathrm{nL}_{w}(490) / \mathrm{nL}_{w}(560)\right]$ vs. in-situ Chl concentrations $\left(\mathrm{mg} \mathrm{m}^{-3}\right)$, and MERIS $\left[\mathrm{nL}_{w}(620)\right]$ vs. in-situ SS concentrations $\left(\mathrm{g} \mathrm{m}^{-3}\right)$, for deriving the relevant algorithms and assessing their compatibility in Chl and SS retrievals. Indeed, this part is very essential in support of the process of the validation and merging of different satellite ocean colour products for the global oceans (IOCCG report, 2003).

Figures $9 \mathrm{a}$ and $\mathrm{b}$ show the relationships between the Thuillier $2004\left[\mathrm{~nL}_{w}(\lambda 1) / \mathrm{nL}_{w}(\lambda 2)\right]$ and others $\left[\mathrm{nL}_{w}(\lambda 1) / \mathrm{nL}_{w}(\lambda 2)\right]$ in the SeaWiFS and MERIS wavelength bands: $\lambda 1=490 \mathrm{~nm}$ and $\lambda 2=555 \mathrm{~nm}$ or $560 \mathrm{~nm}$. There exists a linear trend between these ratios that increases with decreasing $\mathrm{Chl}$ concentrations, for the low ratio values relative to high $\mathrm{Chl}$, the others $\left[\mathrm{nL}_{w}(\lambda 1) / \mathrm{nL}_{w}(\lambda 2)\right]$ are seemingly consistent with the Thuillier $2004\left[\mathrm{~nL}_{w}(\lambda 1) / \mathrm{nL}_{w}(\lambda 2)\right]$. However, this tendency changes in relatively clear and turbid waters, where the $\left[\mathrm{nL}_{w}(\lambda 1) / \mathrm{nL}_{w}(\lambda 2)\right]$ of the Neckel and Labs 1984, Wehrli 1985_WMO, ASTM E-490, ASTM G173-03 and SBDART ETR tend to go downward from the one-to-one trend line of the Thuillier $2004\left[\mathrm{~nL}_{w}(\lambda 1) / \mathrm{nL}_{w}(\lambda 2)\right]$. In contrast, the Thekaekara $1973\left[\mathrm{~nL}_{w}(\lambda 1) / \mathrm{nL}_{w}(\lambda 2)\right]$ tends to go upward from this trend line of the Thuillier 2004 $\left[\mathrm{nL}_{w}(\lambda 1) / \mathrm{nL}_{w}(\lambda 2)\right]$. These deviations might be larger in the case of SS-dominated waters and with the other ratios involving more bands. Nevertheless, in all these situations the Gueymard $2004\left[\mathrm{~nL}_{w}(\lambda 1) / \mathrm{nL}_{w}(\lambda 2)\right]$ follows the one-to-one trend line of the Thuillier $2004\left[\mathrm{~nL}_{w}(\lambda 1) / \mathrm{nL}_{w}(\lambda 2)\right]$ in the SeaWiFS and MERIS bands.

Figures $9 \mathrm{c}$ and $\mathrm{d}$ show the relationships between the log-transformed SeaWiFS $\left[\mathrm{nL}_{w}(490) / \mathrm{nL}_{w}(555)\right]$ and MERIS [ $\left.\mathrm{nL}_{w}(490) / \mathrm{nL}_{w}(560)\right]$ and log-transformed in-situ chlorophyll concentrations (in a diverse range of waters containing Chl $=0.1-107 \mathrm{mg} \mathrm{m}^{-3}, \mathrm{SS}=0.13-120 \mathrm{~g} \mathrm{~m}^{-3}$, and $\left.\mathrm{DOM}=0.01-2 \mathrm{~m}^{-1}\right]$. The statistical analysis of these relationships allowed us to derive the best-fit power function equations with high correlation coefficients $\left(\mathrm{r}^{2}\right)$ for both SeaWiFS and MERIS sensors (Table 6). In these regression equations, the exponent of the power function is constant for all irradiance cases, but the constant of proportionality seems to be variable - low for the Wehrli 1985_WMO, ASTM E-490, Neckel and Labs 1984, SBDART ETR and ASTM G173-03, medium for the Thuillier 2004 and Gueymard 2004, and high for the Thekaekara 1973. The correlation coefficient tends to be around 0.87 for all SeaWiFS algorithms and 0.88 for all MERIS algorithms. All the developed 

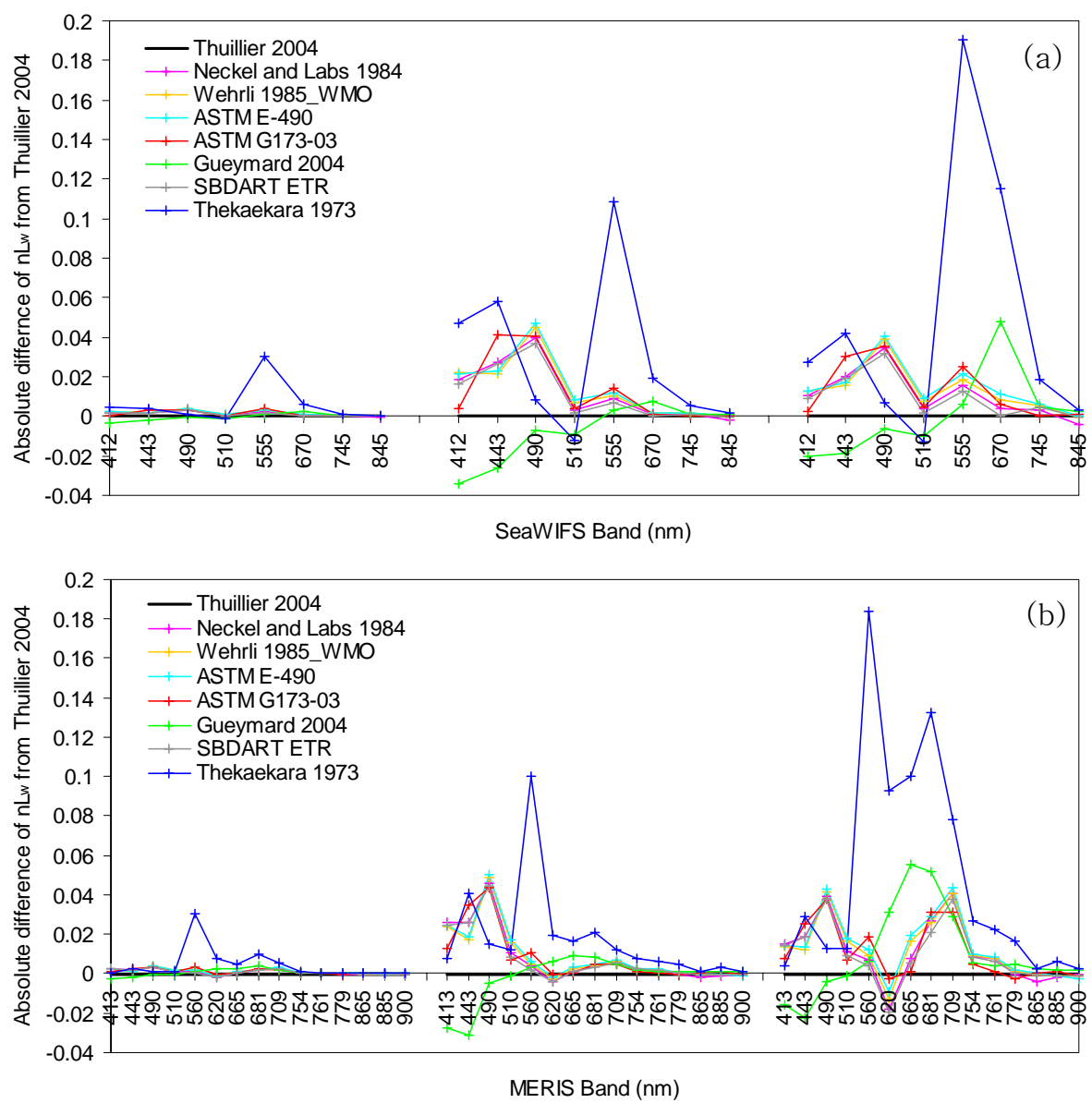

Fig. 7. The absolute $\mathrm{nL}_{w}$ differences between the Thuillier 2004 and other spectra in SeaWiFS and MERIS channels.

algorithms were tested on our recent cruise data and the results revealed the differences of $<0.01 \mathrm{mg} \mathrm{m}^{-3}$ at $\mathrm{Chl} \mathrm{re-}$ trievals in both clear and turbid coastal waters. This suggests that there would be a less significant impact of adopting different solar irradiance spectra on the spectral ratios algorithms for retrieving the phytoplankton pigment concentrations in ocean waters.

Figure 10a shows the scatter plot of the MERIS_Others $\left[\mathrm{nL}_{w}(620)\right]$ versus MERIS_Thuillier 2004 [ $\left.\mathrm{nL}_{w}(620)\right]$. Note that the MERIS_Others [ $\left.\mathrm{nL}_{w}(620)\right]$ deviate downward from the one-to-one line of the MERIS_Thuillier $2004\left[\mathrm{~nL}_{w}(620)\right]$ and this deviation is larger with high $\mathrm{nL}_{w}$ values observed in sediment-dominated coastal waters. To illustrate the impact of such a deviations on SS retrieval, the best-fit exponential function relationships were developed between the log-transforms of MERIS $\left[\mathrm{nL}_{w}(620)\right]$ and in-situ SS concentrations (in waters containing $\mathrm{SS}=1-55 \mathrm{~g} \mathrm{~m}^{-3}, \mathrm{Chl}=1-$ $5 \mathrm{mg} \mathrm{m}^{-3}$ and DOM $=0.12-2 \mathrm{~m}^{-1}$ ) and the regression coefficients (including $\mathrm{r}^{2}=0.94$ ) were derived (Fig. 10b, Table 6). This plot reveals a close consistency among the relationships of the eight irradiance spectra. The results of testing these algorithms on the recent cruise data confirmed that there was

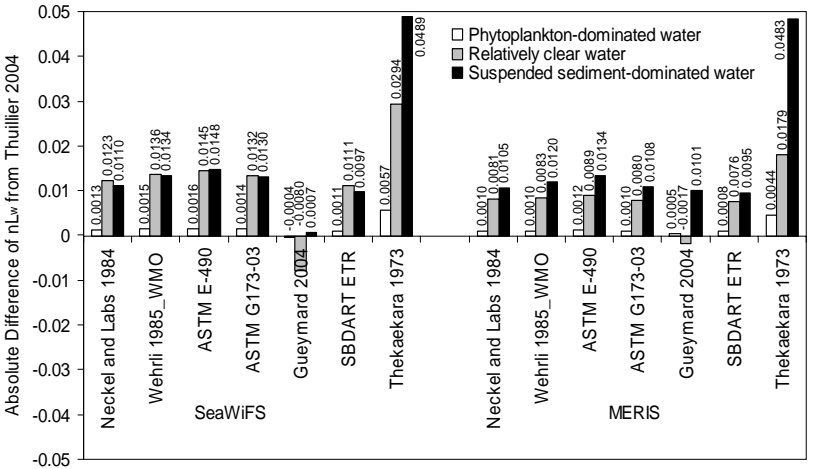

Fig. 8. The band-averaged $\mathrm{nL}_{w}$ differences between the Thuillier 2004 and other spectra in three cases of the waters.

a less significant impact of adopting different solar irradiance spectra on the single band algorithms for retrieving the suspended sediment concentrations in coastal waters. 

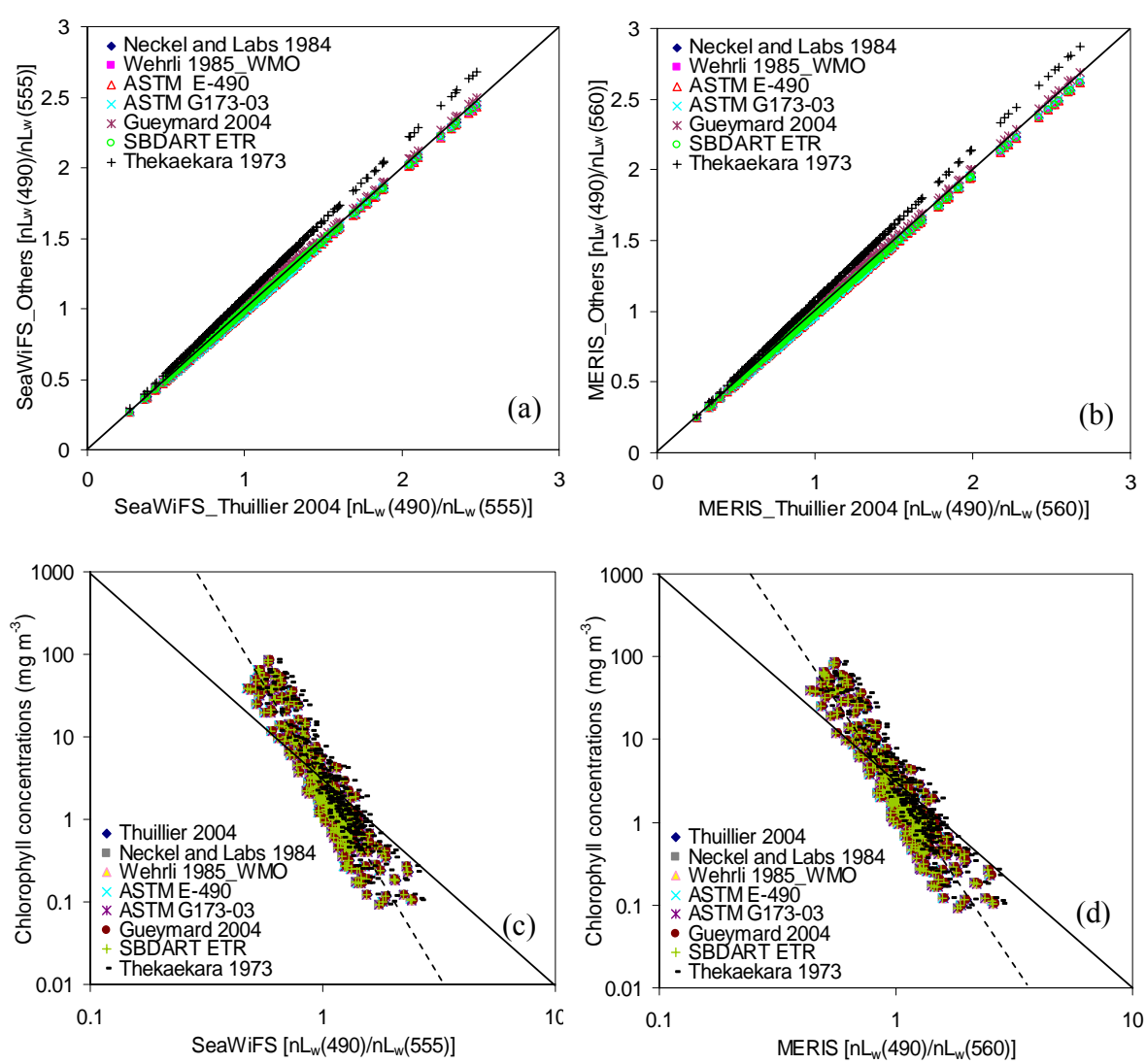

Fig. 9. (a) and (b) Scatter plots of the SeaWiFS_Others [nLw(490)/nLw(555)] and MERIS_Others [nLw(490)/nLw(560)] versus SeaWiFS_Thuillier 2004 [nLw(490)/nLw(555)] and MERIS_Thuillier 2004 [nLw(490)/nLw(560)]. Others are the ratios from the Neckel and Labs 1984, Wehrli 1985_WMO, ASTM E-490, ASTM G173-03, Gueymard 2004, SBDART ETR and Thekaekara 1973. (c) and (d) Log-log plots of the SeaWiFS [nLw(490)/nLw(555)] and MERIS [nLw(490)/nLw(560)] as a function of the in-situ Chl concentrations. The total number of observations, $\mathrm{N}=338$. Note that once again the Thekaekara 1973 proves to be different than the others.

Table 6. The retrieval algorithms of chlorophyll and suspended sediment predicted for SeaWiFS and MERIS for the different solar irradiance models.

\begin{tabular}{llll}
\hline Solar irradiance spectrum & SeaWiFS & MERIS & MERIS \\
\hline Thuillier 2004 & $\mathrm{Chl}=2.646[\mathrm{XX}]^{-4.578}$ & $\mathrm{Chl}=2.637[\mathrm{XX}]^{-4.185}$ & $\mathrm{SS}=0.983 \mathrm{e}^{1.053 X}$ \\
Neckel and Labs 1984 & $\mathrm{Chl}=2.465[\mathrm{XX}]^{-4.578}$ & $\mathrm{Chl}=2.399[\mathrm{XX}]^{-4.185}$ & $\mathrm{SS}=0.983 \mathrm{e}^{1.045 X}$ \\
Wehrli 1985_WMO & $\mathrm{Chl}=2.445[\mathrm{XX}]^{-4.578}$ & $\mathrm{Chl}=2.392[\mathrm{XX}]^{-4.185}$ & $\mathrm{SS}=0.983 \mathrm{e}^{1.047 X}$ \\
ASTM E-490 & $\mathrm{Chl}=2.446[\mathrm{XX}]^{-4.578}$ & $\mathrm{Chl}=2.393[\mathrm{XX}]^{-4.185}$ & $\mathrm{SS}=0.983 \mathrm{e}^{1.049 X}$ \\
ASTM G173-03 & $\mathrm{Chl}=2.502[\mathrm{XX}]^{-4.578}$ & $\mathrm{Chl}=2.459[\mathrm{XX}]^{-4.185}$ & $\mathrm{SS}=0.983 \mathrm{e}^{1.052 X}$ \\
Gueymard 2004 & $\mathrm{Chl}=2.726[\mathrm{XX}]^{-4.578}$ & $\mathrm{Chl}=2.695[\mathrm{XX}]^{-4.185}$ & $\mathrm{SS}=0.983 \mathrm{e}^{1.067 X}$ \\
SBDART ETR & $\mathrm{Chl}=2.467[\mathrm{XX}]^{-4.578}$ & $\mathrm{Chl}=2.394[\mathrm{XX}]^{-4.185}$ & $\mathrm{SS}=0.983 \mathrm{e}^{1.045 X}$ \\
Thekaekara 1973 & $\mathrm{Chl}=3.804[\mathrm{XX}]^{-4.578}$ & $\mathrm{Chl}=3.543[\mathrm{XX}]^{-4.185}$ & $\mathrm{SS}=0.983 \mathrm{e}^{1.095 X}$ \\
Correlation coefficient $\left(\mathrm{r}^{2}\right)$ & 0.87 & 0.88 & 0.94 \\
\hline
\end{tabular}

$\mathrm{XX}=\left[\mathrm{nL}_{w}(490) / \mathrm{nL}_{w}(555)\right]$ in the case of SeaWiFS or $\left[\mathrm{nL}_{w}(490) / \mathrm{nL}_{w}(560)\right]$ in the case of MERIS for which $\mathrm{X}=\left[\mathrm{nL}_{w}(620)\right]$

\section{Discussion and conclusions}

For ocean colour remote sensing applications, the choice of a solar irradiance spectrum is dependent on the minimal differ- ences/errors, minimum spectral range of 350-1200 $\mathrm{nm}$ with adequate spectral resolution, completely or mostly based on direct measurements and update of data. In spite of this, the remote sensing community had adopted the different 
solar irradiance spectra in their data processing, and calibration and validation of various satellite sensors, for instance, the Neckel and Labs 1984 for IRS-P3 MOS, SeaWiFS and MODIS (Suemnich, 1998; Barnes and Zalewski, 2003), the Wehrli 1985_WMO for MODIS and Hyperion (Doelling et al., 2004), and the Thuillier 2001 and Thuillier 2003 for GLI, MERIS, SeaWiFS and MODIS (Delwart, 2001 ${ }^{1}$; Nieke and Fukushima, 2001, Barnes and Zalewski, 2003; Brown et al., 2004). The differences in these irradiance spectra could lead to an incompatibility in the TOA radiances (calibrated through the use of a reference illuminated by the Sun and then expressed in absolute units by adopting a solar irradiance spectrum), normalization of water-leaving radiance, calibration and interpretation of atmospheric radiation measurements, and atmospheric correction algorithms for all satellite ocean colour measurements.

This study intended to make an intercomparison of eight solar irradiance spectra in the absolute forms and in the in-band irradiances computed using the spectral response functions of the SeaWiFS and MERIS's channels. This study also analyzed the impact of their differences on the retrieval algorithms of chlorophyll and suspended sediment predicted for the SeaWiFs and MERIS sensors. Such an intercomparison showed some specific problems in these spectra, as demonstrated in Sect. 5.1. In both the absolute and in-band irradiances, the Thekaekara 1973 spectrum showed large differences with the Thuillier 2004 and other spectra, particularly in the green-NIR domain. This might result from low-altitude aircraft measurements, together with terrestrial absorption features (by ozone and water vapour), inefficient calibration methods and experimental problems, and conflicting determinations of solar constant $\left(1352.5 \mathrm{~W} \mathrm{~m}^{-2}\right.$ ) (Frohlich, 1983). Though the Neckel and Labs 1984, Wehrli 1985_WMO, ASTM and SBDART ETR were quite similar in their spectral forms, they showed significant differences with the Thuillier 2004 spectrum. As was noted before by Harrison et al. (2003) and Thuillier et al. (2004), the Neckel and Labs 1984 spectrum was low below $450 \mathrm{~nm}$ and high above $850 \mathrm{~nm}$ and presented the lack of a set of measured solar irradiances beyond $1150 \mathrm{~nm}$. The Wehrli 1985_WMO spectrum was not only high in the NIR but also displayed anomalous dips above $900 \mathrm{~nm}$, owing to inaccuracies or biases from rutted smoothening and scaling process used to concatenate data sets obtained with very different methods. Perhaps the inaccuracy could also be due to atmospheric interferences with the Smith and Gottlieb spectrum and other older spectra from Arvesen et al. (1969) and Pierce (1954) on which Wehrli based his spectrum. The ASTM spectra showed an improvement over Wehrli's spectrum, but they presented slight problems in the ultravioletvisible and NIR domains, due to the low overall scaling factor. Furthermore, its resolution is limited to $1 \mathrm{~nm}$ below $630 \mathrm{~nm}$ and $2 \mathrm{~nm}$ above it, which may not be adequate for modern remote sensing applications. The SBDART ETR spectrum seemed to be almost similar to that of the Neckel
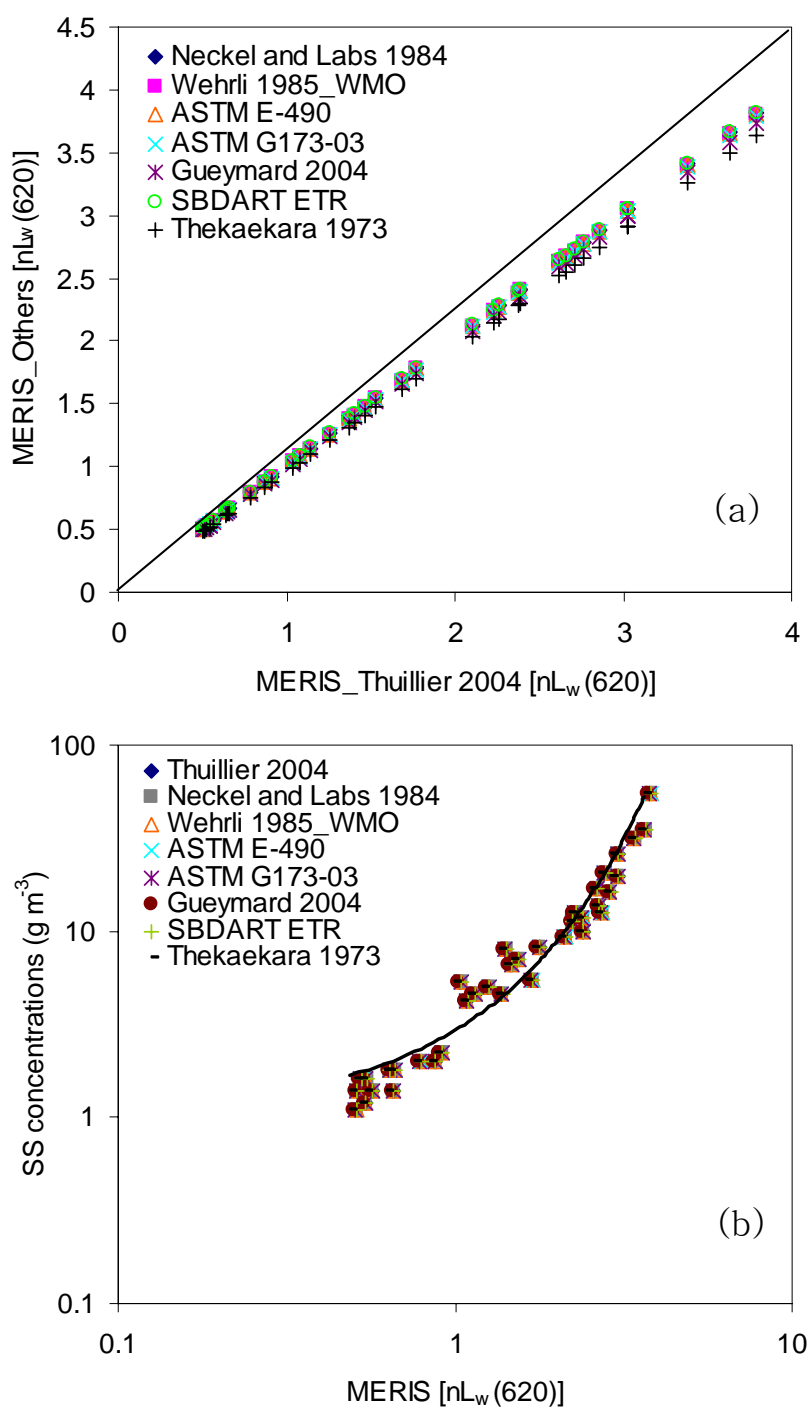

Fig. 10. (a) Scatter plot of the MERIS_Others [nLw(620)] versus MERIS_Thuillier 2004 [nLw(620)]. Others are the Neckel and Labs 1984, Wehrli 1985_WMO, ASTM E-490, ASTM G173-03, Gueymard 2004, SBDART ETR and Thekaekara 1973. (b) Log-log plot of the MERIS [nLw(620)] as a function of the in-situ SS concentrations. The total number of observations, $\mathrm{N}=37$.

and Labs 1984 spectrum, and its inconsistency with the Thuillier 2004 spectrum could be due to source data reported by Thekaekara (1973). On the contrary, the Gueymard 2004 spectrum closely agreed with the Thuillier 2004 spectrum, although fluctuating in the ultraviolet-blue and red wavelength domains.

The detailed investigation of this study reveals that the Thuillier 2004 spectrum (from the modern SOLSPEC instrument, currently re-calibrated and in preparation for new experiments which promise the desired update of the former standards by overcoming the problem of atmospheric interferences and by providing updates for the next solar cycle) is 
more appropriate for current and future research and related investigations in ocean colour remote sensing, as it provides an incremental improvement over other spectra with significantly more irradiance values, particularly at wavelengths shorter than $400 \mathrm{~nm}$ and longer than $700 \mathrm{~nm}$ (with an estimated error of $<2 \%$ in the visible and NIR and $3 \%$ in the UV domain). The more accurate irradiance values in the UV domain are highly suitable for the near future investigations that will directly measure the UV part of the spectrum, particularly to elucidate and quantify the global distributions of colored dissolved organic material and absorbing aerosols (strong UV absorbers). Thus, the model of Thuillier et al. (2004), representing the current state of the art in solar irradiance spectra, is suggested to be the best candidate model for the ocean colour remote sensing and related applications (Table 1). Since the Thuillier 2004 adopts the conflicting determination of solar constant $\left(1366.7 \mathrm{~W} \mathrm{~m}^{-2}\right)$, this study proposes a new solar constant value $1366.1 \mathrm{~W} \mathrm{~m}^{-1}$ to improve the future version of this spectrum. This study also suggests the best use of the Gueymard 2004 spectrum for applications beyond the $2400 \mathrm{~nm}$ maximum range of the Thuillier 2004 spectrum (Table 1).

This study demonstrated that the differences in the solar irradiance spectra would have a less significant impact on the retrieval of chlorophyll and SS concentrations and therefore on the intercomparison or merging of the ocean colour products resulting from different instruments. Indeed, much of the impact on these processes results from the inaccurate atmospheric correction and variable bio-optical algorithms used to process the ocean colour data. The previous studies of calibration and validation indicated that adopting the different solar irradiance spectra would have a less discernable effect on the uncertainty budget of the calibration for any individual satellite ocean colour sensor (Barnes and Zalewski, 2003; Mueller and Morel, 2003).

Acknowledgements. This research work is a part of the Development of Geostationary Ocean Colour Imager (GOCI) supported by the Ministry of Maritime Affairs and Fisheries (MOMAF) through KORDI contract PM 397-00. We thank G. A. Gueymard, Solar Consulting Services, Edgewater, FL, USA, for contributing his data to this work. We are greatly thankful to anonymous reviewers for their valuable comments and suggestions, which helped to improve the scientific content and quality of the manuscript.

Topical Editor S. Gulev thanks two anonymous referees for their help in evaluating this paper.

\section{References}

Acker, J., Alexander, V., Denis, N., and Norman, K.: Use of SeaWiFS ocean colour data to estimate neritic sediment mass transport from carbonate platforms for two hurricane-forced events, Int. J. Rem. Sens., 23, 39-47, 2004.

Ahn, Y. H., Moon, J. E., and Gallegos, S.: Development of suspended particulate matter algorithms for ocean colour remote sensing, Korean J. Rem. Sens., 17, 285-295, 2001.
Ahn, Y. H., Shanmugam, P., Ryu, J. H., and Moon, J. E.: The derivation and evaluation of suspended sediment algorithms for optical remote sensing of the coastal turbid waters, Proceedings of the $8^{\text {th }}$ International Conference on Remote Sensing for Marine and Coastal Environments, Halifax, Nova Scotia, Canada, 17-19 May 2005.

Ahn, H. and Shanmugam, P.: Detecting red tides from satellite ocean colour observations in optically complex Northeast-Asia coastal waters, Rem. Sens. Environ., 103, 419-437, 2006.

Aiken, J., Moore, G. F., Trees, C. C., Hooker, S. B., and Clark, D. K.: The SeaWiFS CZCS-type pigment algorithm, NASA Technical Memorandum 104566, vol. 29, 1995.

Arvesen, J. C., Griffin, R. N., and Pearson, B.: Determination of extraterrestrial solar spectral irradiance from a research aircraft, Appl. Opt., 8, 2215-2232, 1969.

ASTM: http://rredc.nrel.gov/solar/spectra/am0, 2000.

Austin, R. W.: Inherent spectral radiance signatures of the ocean surface, In: Ocean colour analysis, Scripps Institute of Oceanography, La Jolla, CA, 1974.

Bailey, S. W. and Werdell, P. J.: A multi-sensor approach for the on-orbit validation of ocean colour satellite data products, Rem. Sens. Environ., 102, 12-23, 2006.

Barnes, R. A. and Zalewski, E. F.: Reflectance-based calibration of SeaWiFS. II. Conversion to radiance, Appl. Opt., 42, 1648-1660, 2003.

Bezy, J.-L., Delwart, S., and Rast, M.: MERIS - A new generation of ocean colour sensor onboard Envisat, ESA Bulletin, 103, 48$56,2000$.

Binding, C. E., Bowers, D. G., and Mitchelson-Jacob, E. G.: An algorithm for the retrieval of suspended sediment concentrations in the Irish Sea from SeaWiFS ocean colour satellite imagery, Int. J. Rem. Sens., 24, 3791-3806, 2003.

Brown, S. W., Clark, D. K., Johnson, B. C., Yoon, H., Lykke, K. R., Flora, S. J., Feinholz., M. E., ouaidia, N., Pietras, C., Stone, T. C., Yarbrough, M. A., Kim, Y. S., Barnes, R. A., and Mueller, J. L.: Advances in radiometry for ocean colour, In: Ocean Optics Protocols for Satellite Ocean Colour Sensor Validation, NASA/TM-2004/Revision 5, Vol.6, GSFSC, Greenbelt, Maryland, USA, 2004.

Clark, D. K.: Algorithm theoretical basis document - Bio-optical algorithms, Case I waters, MODIS algorithm theoretical basis document 18, Version 1.2, available from: http://modis.gsfc. nasa.gov/data/atbd/atbd_mod18.pdf, 1997.

Darecki, M. and Stramski, D.: An evaluation of MODIS and SeaWiFS bio-optical algorithms in the Baltic Sea, Rem. Sens. Environ., 89, 326-350, 2004.

Doelling, D. R., Minnis, P., and Nguyen, L.: Calibration comparisons between SEVIR, MODIS and GOES data, MSG RAO Workshop, Salzburg, Austria, 2004.

Doxaran, D., Froidefond, J. M., Lavender, S., and Castaing, P.: Spectral signature of highly turbid waters. Application with SPOT data to quantify suspended particulate matter concentrations, Rem. Sens. Environ., 81, 149-161, 2002.

Dozier, J. and Frew, J.: Atmospheric corrections to satellite radiometric data over rugged terrain, Rem. Sens. Environ., 11, 191205, 1981.

Fligge, M. and Solanki, S. K.: The solar spectra irradiance since 1700, Geophys. Res. Lett., 27, 2157-2160, 2000.

Frohlich, C.: Data on total and spectral irradiance: comments, Appl. 
Opt., 22, 3928, 1983.

Frohlich, C.: Solar irradiance variability, In: Solar variability and its effects on climate, Geophysical Monograph 141, American Geophysical Union, 2004.

Gitelson, A., Mayo, M., and Yacobi, Y. Z.: Signature analysis of reflectance spectra and its application for remote observation of the phytoplankton distribution in Lake Kinneret, International Society for Photogrammetry and Remote Sensing 6th International Symposium, Val d'Isere, France, 277-283, 1994.

Gordon, H. R.: Removal of atmospheric effects from satellite imagery of the oceans, Appl. Opt., 17, 1631-1636, 1978.

Gordon, H. R. and Clark, D. K.: Clear water radiances for atmospheric correction of Coastal Zone Colour Scanner Imagery, Appl. Opt., 20, 4174-4180, 1981.

Gordon, H. R.: Normalized water-leaving radiance: Revisiting the influence of surface roughness, Appl. Opt., 44, 241-248, 2005.

Gueymard, C. A.: The sun's total and spectral irradiance for solar energy applications and solar radiation models, Solar Energy, 76, 423-453, 2004

Harrison, L., Kiedron, P., Berndt, J., and Schlemmer, J.: The solar spectrum 360 to $1050 \mathrm{~nm}$ from rotating shadowband spectroradiometer (RSS) measurements at the southern Great Plains Site, J. Geophys. Res., 1080, 4424, doi:10.1029/2001JD001311, 2003.

Hooker, S. B., Firestone, E. R., and Acker, J. C.: SeaWiFS Prelaunch Radiometric Calibration and Spectral Characterization, SeaWiFS technical report series, NASA Technical Memorandum 104566, vol. 23, 1994.

IOCCG Report.: Standardizing the extraterrestrial solar flux spectrum used with ocean-colour sensors, 17th Plenary Meeting, Colourado, USA, 2003.

Jeffrey, S. W. and Humphrey, G. F.: New spectrophotometric equations for determining chlorophyll $\mathrm{a}, \mathrm{b}$ and $\mathrm{c}$ in higher plants, algae and natural phytoplankton, Biochemie Physiologie Pflanzen, 167, 374-384, 1975.

Klemas, V., Bartlett, D., Philpot, W., Rogers, R., and Reed, L.: Coastal and estuarine studies with ERTS-1 and Skylab, Rem. Sens. Environ., 3, 153-163, 1974.

KORDI Report: Preliminary studies and the user requirements of the ocean payloads in geostationary orbit satellites, BSPK04500-1536-1, Korea, 2003.

Kurucz, R. L.: Solar Flux atlas from 296 to 1300 nm, National Solar Observatory Atlas No. 1, NOAO, Sunspot, NM, 1984.

Lean, J.: Variations in the sun's radiative output, Rev. Geophys., 29, 505-535, 1991.

McClain, C. R. and Yeh, E. N.: CZCS bio-optical algorithm comparison, in: Case Studies for SeaWiFS Calibration and Validation, 1, NASA Technical Memorandum 104566, vol. 13, 1994.

Mitchell, B. G.: Global Imager (GLI) standard algorithms (Chla, CDOM and K490): Calibration and validation, GLI progress meeting, available at: http://suzaku.eorc.jaxa.jp/GLI/index.html, 2001.

Mobley, C. D.: Estimation of the remote sensing reflectance from above-sea surface, Appl. Opt., 38, 7442-7455, 1999.

Morel, A. and Prieur, L.: Analysis of variations in ocean colour, Limnol. Oceanogr., 22, 709-722, 1977.

Morel, A. and Gentili, B.: Diffuse reflectance of oceanic waters: III. Implication of bidirectionality for remote sensing problems, Appl. Opt., 37, 4850-4862, 1996.
Morel, A. and Belanger, S.: Improved detection of turbid waters from ocean colour sensors information, Rem. Sens. Environ., 102, 237-249, 2006.

Müller-Karger, F. E., McClain, C. R., Sambrotto, R. N., and Ray, G. C.: A comparison of ship and coastal zone colour scanner mapped distribution of phytoplankton in the southeastern Bering Sea, J. Geophys. Res., 95, 11 483-11 499, 1990.

Mueller, J. L. and Morel, A.: Fundamental definitions, relationships and conventions, In: Ocean Optics Protocols for Satellite Ocean Colour Sensor Validation, NASA/TM-2003-21621/ Revision 4, Vol.1-6, GSFSC, Greenbelt, Maryland, USA, 2003.

Neckel, H. and Labs, D.: The solar radiation between 3300 and 12500, Solar Phys., 205-258, 1984.

Nieke, J. and Fukushima, H.: Selection of a solar reference spectrum for GLI's reflective bands, Earth Observation Research Center (EORC), Triton Square Office Tower X 22F, Harumi Chuo-ku 1-8-10, Tokyo, Japan, 2001.

O’Reilly, J. E., Maritorena, S., Mitchell, B. G., Siegel, D. A., Carder, K. L., Garver, S. A., Kahru, M., and McClain, C.: Ocean colour chlorophyll algorithms for SeaWiFS, J. Geophys. Res., 103, 24 937-24 953, 1998.

O’Reilly, J. E., Maritorena, S., Siegel, D., O’Brien, M. C., Toole, D., Mitchell, B. G., Kahru, M., Chavez, F. P., Strutton, P., Cota, G., Hooker, S. B., McClain, C. R., Carder, K. L., Muller-Karger, F., Harding, L., Magnuson, A., Phinney, D., Moore, G. F., Aiken, J., Arrigo, K. R., Letelier, R., and Culver, M.: Ocean colour chlorophyll a algorithms for SeaWiFS, OC2, and OC4 Version 4, In: SeaWiFS Post launch Technical Report Series, vol. 11, Part 3, NASA, Goddard Space Flight Center, Greenbelt, Maryland, 2000.

Pap, J. M.: Long-term solar-irradiance variability, in: Sounding solar and stellar interiors, edited by: Provost, L. and Schmoder, F. X., IAU Symposium, vol. 181. Kulwer Academic Publishers, Dordrecht, 1998.

Pap, J. M., Turmon, M., Floyd, L., Frohlich, C., and Wehrli, C.: Total solar and spectral irradiance variations from solar cycles 21 to 23, Adv. Space Res., 29, 1923-1932, 2002.

Pinkerton, M. H., Richardson, K. M., Boyd, P. W., Gall, M. P., Zeldis, J., Oliver, M. D., and Murphy, R. J.: Intercomparison of ocean colour band-ratio algorithms for chlorophyull concentration in the Subtropical Front east of New Zealand, Rem. Sens. Environ., 97, 382-402, 2005.

Pierce, A. K.: Relative solar energy distribution in the spectral region 10,000-25,000 Å, Astrophys. J., 119, 312-327, 1954.

Ricchiazzi, P., Yang, S., Gautier, C., and Sole, D.: SBDART: A research and teaching software tool for plane-parallel radiative transfer in the Earth's atmosphere, Bull. Am. Meteorol. Soc., 79, 2101-2114, 1998.

Rottman, G., Floyd, L., and Viereck, R.: Measurement of the solar ultraviolet irradiance, in: Solar variability and its effects on climate, Geophysical Monograph 141, American Geophysical Union, 2004.

Ruddick, K., Park, Y., and Nechad, B.: MERIS imagery of Belgian coastal waters: Mapping of suspended particulate matter and chlorophyll-a, Proceedings of the MERIS Users Workshop, ESA Special Publication SP-549, 2003.

Smith, E. V. P. and Gottlieb, D. M.: Solar flux and its variations, Space Sci. Rev., 16, 771-802, 1974.

Stumpf, R. P. and Pennock, J. R.: Remote estimation of the diffuse 
attenuation coefficient in a moderately turbid estuary, Rem. Sens. Environ., 38, 182-191, 1991.

Sumnich, K. H.: In-flight calibration of the Modular Optoelectronic Scanner (MOS), Int. J. Rem. Sens., 19, 3237-3259, 1998.

Taylor, M.: IKONOS Planetary reflectance and mean solar exoatmospheric irradiance, IKONOS Planetary Reflectance, QSOL Rev. 1, Space Imaging, CO, USA, 2005.

Thekaekara, M. P.: Extraterrestrial solar spectral irradiance, in: The Extraterrestrial Solar Spectrum, edited by: Drummond, A. J. and Thekaekara, M. P., Institute of Environmental Studies, Mot Prospect, IL, 1973.

Thekeakara, M. P.: Extra-Terrestrial solar spectrum, 3000-6100 A at $1 \mathrm{~A}$ intervals, Appl. Opt., 13, 518-522, 1974.

Thuillier, G., Floyd, L., Woods, T. N., Cebula, R., Hilsenrath, E., Herse, M., and Labs, D.: Solar Irradiance Reference Spectra, in: Solar Variability and its Effect on the Earth's Atmosphere and Climate System, edited by: Pap, J. M., Fox, P., Frohlich, C., Hudson, H. S., Kuhn, J., McCormack, J., North, G., Sprigg, W., and $\mathrm{Wu}, \mathrm{S}$. T., American Geophysical Union, Washington, D.C., 171-194, 2004.
VanHoosier, M. E., Bartoe, J. D., Brueckner, G. E., and Prinz, D. K.: Absolute solar spectral irradiance $120 \mathrm{~nm}-400 \mathrm{~nm}$ : Results from the Solar Ultraviolet Spectral Irradiance Monitor (SUSIM) experiment on board Spacelab 2, Astrophys. Lett. Commun., 27, 163-168, 1988.

Wehrli, C.: Extraterrestrial Solar Spectrum, Publication no. 615, Physikalisch-Meteorologisches Observatorium + World Radiation Center (PMO/WRC) Davos Dorf, Switzerland, 1985.

Willson, R. C. and Hudson, H. S.: Variations of solar irradiance, The Astrophys. J., 244, 185-189, 1981.

Woods, T. N., Prinz, D. K., Rottman, G. J., London, J., Crane, P. C., Cebula, R. P., Hilsenrath, E., Brueckner, G. E., Andrews, M. D., White, O. R., VanHoosier, M. E., Floyd, L. E., Herring, L. C., Knapp, B. G., Pankratz, C. K., and Reiser, P. A.: Validation of the UARS solar ultraviolet irradiances: Comparison with the ATLAS 1 and 2 measurements, J. Geophys. Res., 101, 95419570, 1996. 